\title{
Transações Inter-Regionais e Intersetoriais entre as Macro-Regiões Brasileiras em 1985 e 1995*
}

\author{
Rossana Lott Rodrigues ${ }^{* *}$ \\ Antonio Carlos Moretto ${ }^{* * *}$ \\ Francisco Constantino Crocomo \\ Joaquim José Martins Guilhoto ${ }^{* * * * *}$
}

Sumário: 1. Introdução; 2. A conjuntura econômica brasileira nas décadas de 80 e 90; 3. Método de análise; 4. Análise dos resultados.

Palavras-chave: economia regional; insumo-produto; transações intersetoriais e inter-regionais.

Códigos JEL: C67; O18; R15.

Este artigo tem como objetivo estudar a evolução da estrutura produtiva das 5 grandes regiões brasileiras nos anos de 1985 e 1995 por meio das matrizes inter-regionais de insumo-produto estimadas a partir das matrizes nacionais publicadas pelo IBGE. Os resultados apontam setores-chave nas cinco regiões estudadas, mostram que a região Sudeste revelou-se bastante independente do resto do Brasil e que as regiões Sul e Nordeste alternaram-se na segunda posição em termos de dinâmica de suas estruturas produtivas, seguidas pelas regiões Centro-Oeste e Norte. Detectou-se, também, certa dinâmica na estrutura produtiva da região Nordeste, bem como a existência de maior integração entre essa e a região Norte em 1995, o que pode estar indicando a existência de certo pólo de desenvolvimento entre essas regiões. Por fim, constatou-se maior independência entre as regiões brasileiras, sendo plausível apontar para o crescimento da integração da estrutura produtiva nacional com o exterior em 1995 relativamente a 1985.

The aim of this article is to study the evolution of the produc-

\footnotetext{
${ }^{*}$ Artigo recebido em dez. 2001 e aprovado em fev. 2005. Agradecemos os comentários de dois pareceristas anônimos.

** Professora do Departamento de Economia da Universidade Estadual de Londrina - Paraná. E-mail: rlott@uel.br

${ }^{* * *}$ Professor do Departamento de Economia da Universidade Estadual de Londrina - Paraná. E-mail: acmoretto@uel.br

${ }^{* * * *}$ Professor do Departamento de Economia da Universidade Metodista de Piracicaba (UNIMEP). E-mail: francisco.crocomo@merconet.com.br

***** Professor Titular da FEA-USP, professor do Regional Economics Applications Laboratory (REAL), University of Illinois, e pesquisador do CNPq. E-mail: guilhoto@usp.br
} 
tive structure of the five Brazilian macro regions in the years 1985 and 1995 by means an interregional input-output tables estimated from the national tables published by IBGE. The results show the key-sectors in the five studied regions, that the Southeast region is very independent from the other Brazilian regions and that the South and Northeast regions alternated in the second position in terms of the dynamics of their productive structures, followed by the Central-West and North regions. It was possible to detect relative dynamics in the productive structure of the Northeast region, as well as the existence of greater integration between that and North region in 1995, which may be indicating the existence of a possible development pole between those regions. Finally, greater independence was verified among the Brazilians regions, being relatively plausible to point at the growth of the integration of the national productive structure with the exterior in 1995 compared to 1985 .

\section{Introdução}

As mudanças em curso na economia brasileira nos últimos anos levantam diversas questões a respeito do nosso futuro, notadamente no que se refere à estrutura intersetorial e inter-regional.

A partir de meados dos anos 80, tinha-se a impressão de que o Brasil havia implantado uma estrutura industrial 'completa, integrada e diversificada'. Daí em diante, as alterações iniciadas com a crise da dívida externa, e que se estendem até o processo de abertura comercial e financeira dos dias de hoje, deram lugar a reflexões e estudos que alteraram as crenças anteriores.

E o que dizer dos setores Agropecuária e, principalmente, Serviços? No âmago destas intensas transformações, como se posicionam as diversas regiões brasileiras em relação às suas estruturas produtivas? Como se desenvolveram as relações inter-regionais?

Este artigo tem por objetivo analisar a estrutura inter-regional e intersetorial da economia brasileira entre os anos de 1985 e 1995, utilizando como instrumental a análise insumo-produto, notadamente as abordagens de Rasmussen (1956) e Hirschman (1958) e Guilhoto et alii (1996).

Para tanto, utilizando-se as matrizes nacionais de insumo-produto de 1985 e 1995 (IBGE, 1995, 1997a) estimou-se as matrizes inter-regionais para as 5 grandes regiões brasileiras, Norte, Nordeste, Centro-Oeste, Sudeste e Sul que, por sua vez, são compostas dos seguintes Estados: Região Norte: Amazonas, Pará, Acre, Amapá, Roraima e Rondônia; Região Nordeste: Maranhão, Piauí, Ceará, Rio 
Grande do Norte, Paraíba, Alagoas, Sergipe, Bahia, Pernambuco e Fernando de Noronha (arquipélago considerado parte do estado de Pernambuco); Região Sudeste: São Paulo, Rio de Janeiro, Minas Gerais, Espírito Santo; Região Sul: Paraná, Santa Catarina e Rio Grande do Sul e Região Centro-Oeste: Mato Grosso, Mato Grosso do Sul, Goiás, Tocantins e Distrito Federal. ${ }^{1}$

Além desta introdução, o artigo está dividido em 4 seções: a segunda apresenta um rápido cenário da economia brasileira nas décadas de 80 e 90 para caracterizar a conjuntura econômica no período 85/95; a terceira descreve a metodologia usada no estudo; a quarta discute os resultados e, finalmente, a quinta trata das considerações finais.

\section{A Conjuntura Econômica Brasileira nas Décadas de 80 e 90}

Os anos 80 registraram um desempenho completamente atípico, considerando a tendência de crescimento de longo prazo da economia brasileira até então registrada. Entre 1980 e 1990 a produção industrial caiu, cerca de, 2\% acumulados, a taxa de crescimento da agricultura diminuiu 2,4\% a.a., enquanto o PIB aumentou apenas 16,8\%, em média, 1,56\% a.a. A exceção foi o setor serviços que, no mesmo período, expandiu-se a uma taxa média de 2,8\% a.a. (Bonelli e Gonçalves, 1998).

A década de 90 foi marcada por dois sub-períodos distintos no que se refere a crescimento econômico e dinamismo. No período 1990-93, a economia nacional passou por um processo de recessão, com o PIB crescendo a uma taxa média de apenas $1,2 \%$ a.a.. Esta taxa foi de $0,3 \%$ para a indústria e 2,3\% para a agricultura. Diante do quadro de recessão e abertura de mercado no qual estava inserido o setor industrial neste período, o processo de ajustamento à realidade competitiva ocorreu sob o domínio de elementos de caráter organizacional. Cabe destacar, neste contexto, os programas de contenção de despesas e racionalização dos métodos produtivos e gerenciais, com objetivo de elevar a produtividade, aprimorar a qualidade dos produtos e reduzir as necessidades de capitais de terceiros (Bonelli e Gonçalves, 1998).

O segundo sub-período (1993-97) apresentou comportamento mais favorável do PIB, atingindo taxa de crescimento pouco superior a 4,4\% a.a. em média, taxa essa que foi de 3,8\% no caso da indústria e de $6 \%$ no da agricultura. Quanto ao setor serviços, a taxa média de crescimento ao longo dos anos 90 foi de 3,1\% a.a. (Bonelli e Gonçalves, 1998).

\footnotetext{
${ }^{1} \mathrm{Na}$ matriz inter-regional de 1985 (Crocomo, 1998), o Estado de Mato Grosso foi considerado integrante da Região Norte. Por outro lado, a matriz inter-regional de 1995 (Guilhoto, 1999) inclui este Estado na Região Centro-Oeste, seguindo o critério do IBGE. 
Nos anos 1993-95 o setor líder do crescimento da economia foi a indústria, que teve a produção 15,5\% maior no primeiro trimestre de 1995 relativamente ao mesmo período do ano anterior, resultado da utilização de $80 \%$ da capacidade industrial. A taxa de investimento, que por mais de dez anos havia sido baixa, alcançou 16,3\% do PIB em 1994, e 19,24\% em 1995. A maior parte desse aumento de investimento deveu-se ao setor privado (Baer (1996) e Conjuntura Econômica (1997)).

A qualidade do investimento também melhorou, crescendo a proporção das aplicações em peças e bens de capital, em grande parte, importados. Isto contribuiu para um aumento significativo na produtividade da mão-de-obra, com a conseqüente elevação nos salários de 5,7\% em 93 e de $6,2 \%$ em 95, relativamente aos anos anteriores; as taxas de desemprego se reduziram para 5,3\% em 1993 e 4,6\% em 1995 (IBGE (1997b) e Conjuntura Econômica (1997)).

O bom desempenho do setor industrial na década de 90 não ofuscou a importância do setor serviços que vem se acentuando ao longo destes anos, notadamente em função dos movimentos de terceirização e terciarização que têm acompanhado as grandes transformações da indústria, sobretudo a partir do início do processo de abertura externa, iniciado em 1990 (Bonelli e Gonçalves, 1998).

Aliás, o processo de abertura da economia, conjugado com as reformas estruturais iniciadas no final da década de 80 e aceleradas na de 90 (dentre elas a privatização e a modernização da economia) e o Plano Real, decretado em julho de 1994, podem ser considerados como os grandes responsáveis pela mudança dos cenários entre os anos 80 e 90.

Finalmente, cabe ressaltar algumas tendências do desempenho setorial brasileiro no período 1985/95. No que se refere ao setor industrial, a característica mais marcante é certa estabilidade da estrutura produtiva associada ao processo de redução do seu share no PIB (a preços correntes). Em 1985, a participação da indústria no produto total era de cerca de $48 \%$, valor que se reduziu para cerca de $42 \%$ em 1990 e 34\% em 1995. Paralelamente, o setor serviços apresentou trajetória semelhante à evolução dos países desenvolvidos, com participações em torno de 40\%, 47\% e 54\%, respectivamente. A agricultura, praticamente manteve sua participação no produto, com $12 \%, 11 \%$ e $12 \%$ para os três anos citados (Melo et alii, 1998). 


\section{Método de Análise}

\section{1 Índices de Rasmussen-Hirschman}

Os índices de ligações de Rasmussen-Hirschman têm sido muito aplicados e comentados na literatura por McGilvray (1977), Hewings (1982), Guilhoto et alii (1994), dentre outros. Essas medidas, inicialmente idealizadas por Rasmussen (1956), foram usadas como meio de identificar setores-chave por Hirschman (1958).

Considerando a estrutura interna da economia, o modelo de insumo-produto inter-regional e seguindo os dois últimos autores, é possível determinar os setores que teriam o maior poder de encadeamento dentro da economia, isto é, realizar o cálculo dos índices de ligações para trás, que estimam o quanto um setor demanda dos outros setores, e dos índices de ligações para frente, que informam o quanto um setor é demandado pelos outros. Para Rasmussen e Hirschman, valores maiores do que 1 dos índices de ligações para trás ou para frente, indicam setores acima da média e, portanto, setores-chave para o crescimento da economia. Esses índices são muito usados, também, para identificar os níveis de integração espacial, ou seja, a interdependência intra, inter e extra regional, razão pela qual os mesmos serão gerados neste estudo tanto para as regiões quanto para o sistema inter-regional formado pelas 5 grandes regiões brasileiras.

Desse modo, com base na equação $L=(I-A)^{-1}$, define-se $l_{i j}$ como um elemento da matriz inversa de Leontief, $L, L^{*}$ como a média de todos os elementos de $L$ e $L_{\bullet j}$ e $L_{i} \bullet$ como a soma dos elementos de uma coluna e de uma linha típica de $L$, dada, respectivamente, por:

$$
L_{\bullet j}=\sum_{i=1}^{n} l_{i j} \quad \text { e } \quad L_{i} \bullet \sum_{i=1}^{n} l_{i j} \quad i, j=1,2, \ldots n
$$

Assim:

Índices de ligações para trás:

$$
U_{j}=\left\lfloor L_{\bullet j / n} / L^{*}\right\rfloor
$$

Índices de ligações para frente:

$$
U_{i}=\left\lfloor L_{i \bullet / n} / L^{*}\right\rfloor
$$




\subsection{Abordagem GHS: os índices puros de ligação}

Os índices de ligações de Rasmussen-Hirschman, embora largamente usados, são criticados por não levar em consideração os diferentes níveis de produção em cada setor da economia. Com o intuito de corrigir essa deficiência, foi proposto, inicialmente, o enfoque Cella-Clements (Cella (1984) e Clements (1990)), posteriormente a visão do índice puro de ligações (Guilhoto et alii, 1994) e, mais recentemente, a abordagem do novo índice puro de ligações, também, denominada GHS (Guilhoto et alii, 1996).

O novo índice puro de ligações, daqui por diante denominado de GHS, será utilizado neste estudo por permitir identificar os graus dos impactos na demanda final em determinadas regiões ou setores, bem como dimensionar as interações entre setores e regiões em termos de valor da produção.

Partindo da consolidação da abordagem GHS apresentada em Guilhoto et alii (1996), a matriz de coeficientes de insumos diretos, $A$, representando um sistema de insumo-produto para duas regiões, $j$ e $r$, é dada por:

$$
A=\left\{\begin{array}{ll}
A_{j j} & A_{j r} \\
A_{r j} & A_{r r}
\end{array}\right\}
$$

em que $A_{j j}$ e $A_{r r}$ são matrizes quadradas dos insumos diretos dentro da primeira e da segunda regiões, respectivamente; $A_{r j}$ e $A_{j r}$ representam matrizes retangulares mostrando os insumos diretos comprados pela primeira região e vice-versa.

De (4) chega-se a:

$$
\begin{gathered}
L=(I-A)^{-1}=\left(\begin{array}{cc}
L_{j j} & L_{j r} \\
L_{r j} & L_{r r}
\end{array}\right)=\left(\begin{array}{cc}
\Delta_{j j} & 0 \\
0 & \Delta_{r r}
\end{array}\right) \\
\left(\begin{array}{cc}
\Delta_{j} & 0 \\
0 & \Delta_{r}
\end{array}\right)\left(\begin{array}{cc}
I & A_{j r} \Delta_{r} \\
A_{r j} \Delta_{j} & I
\end{array}\right)
\end{gathered}
$$

cujos elementos são definidos como:

$$
\begin{gathered}
\Delta_{j}=\left(I-A_{j j}\right)^{-1} \\
\Delta_{r}=\left(I-A_{r r}\right)^{-1} \\
\Delta_{j j}=\left(I-\Delta_{j} A_{j r} \Delta_{r} A_{r j}\right)^{-1}
\end{gathered}
$$




$$
\Delta_{r r}=\left(I-\Delta_{r} A_{r j} \Delta_{j} A_{j r}\right)^{-1}
$$

Conjugando a equação (5) com a formulação de Leontief dada por:

$$
X=(I-A)^{-1} Y
$$

é possível derivar um conjunto de índices que podem ser usados para:

a) ordenar as regiões em termos de sua importância no valor da produção gerado e;

b) verificar como ocorre o processo de produção na economia.

Esses índices são obtidos de:

$$
\left(\begin{array}{c}
X_{j} \\
X_{r}
\end{array}\right)=\left(\begin{array}{cc}
\Delta_{j j} & 0 \\
0 & \Delta_{r r}
\end{array}\right)\left(\begin{array}{cc}
\Delta_{j} & 0 \\
0 & \Delta_{r}
\end{array}\right)\left(\begin{array}{cc}
I & A_{j r} \Delta_{r} \\
A_{r j} \Delta_{j} & I
\end{array}\right)\left(\begin{array}{c}
Y_{j} \\
Y_{r}
\end{array}\right)
$$

Fazendo o produto dos três últimos termos do lado direito da equação (11) chega-se a:

$$
\left(\begin{array}{c}
X_{j} \\
X_{r}
\end{array}\right)=\left(\begin{array}{cc}
\Delta_{j j} & 0 \\
0 & \Delta_{r r}
\end{array}\right)\left(\begin{array}{c}
\Delta_{j} Y_{j}+\Delta_{j} A_{j r} \Delta_{r} Y_{r} \\
\Delta_{r} A_{r j} \Delta_{j} Y_{j} \Delta_{r} Y_{r}
\end{array}\right)
$$

em que $A_{j r} \Delta_{r} Y_{r}$ representa o impacto direto da demanda final da região r sobre a região j, isto é, fornece o nível de exportação da região j necessário para satisfazer o nível de produção da região $r$ dada a demanda final $Y_{r}$ e $A_{r j} \Delta_{j} Y_{j}$ mostra o impacto direto da demanda final da região $j$ sobre a região $r$, ou seja, indica o nível de exportação da região $r$ que é necessário para satisfazer a produção da região $j$ para determinada demanda final $Y_{j}$.

A partir de (12) podem ser extraídas as novas definições de índice puro de ligação para trás $(P B L)$ e de índice puro de ligação para frente $(P F L)$ dadas por:

$$
\begin{gathered}
P B L=\Delta_{r} A_{r j} \Delta_{j} Y_{j} \\
P F L=\Delta_{j} A_{j r} \Delta_{r} Y_{r}
\end{gathered}
$$

O PBL representa o impacto puro do valor da produção total da região $j$ sobre a região $r,\left(\Delta_{j} Y_{j}\right)$, ou seja, o impacto que é livre da demanda de insumos que a região $j$ realiza da próprio região $j$ e dos retornos da região $r$ para a região $j$ e 
vice-versa. O PFL indica o impacto puro do valor da produção total da região $r$ sobre a região $j,\left(\Delta_{r} Y_{r}\right)$. Uma vez que o $P B L$ e o $P F L$ são expressos em valores correntes, o índice puro do total das ligações $(P T L)$ de cada setor na economia pode ser obtido pela adição de ambos:

$$
P T L=P B L+P F L
$$

Neste estudo, os índices puros de ligação serão normalizados pelo valor médio dos setores da economia, o que permite verificar a posição de cada setor em relação à média, realizar comparações diretas entre as estruturas produtivas de economias com diferentes tamanhos e moedas, além de comparações temporais entre economias que passaram por sérios processos inflacionários ou por trocas de moeda.

\section{Análise dos Resultados}

\section{1 Índices de ligações de Rasmussen/Hirschman}

A análise dos índices de ligações de Rasmussen/Hirschman para as grandes regiões identifica os setores-chave que dinamizam a economia, tanto pelo grau da demanda por produtos de outros setores, quanto pelo grau da oferta de produtos a outros setores.

Assim, considerando o critério restrito para a determinação dos setores-chave (McGilvray, 1977), as tabelas 1 e 2 destacam os setores com índices para frente e para trás que apresentam, simultaneamente, valores maiores do que 1 , levando em conta as regiões de forma isolada.

Para 1985 e 1995 todas as regiões apresentaram setores-chave, mas os destaques são as regiões Nordeste e Sul. A primeira com 5 setores-chave em 1985 e 3 em 1995, sendo que Metalurgia (4), Química (11) e Indústria Têxtil (14) foram comuns aos dois anos, enquanto na segunda verificou-se os mesmos setores-chave para ambos os anos analisados, Metalurgia (4), Celulose, Papel e Gráfica (9), Indústria Têxtil (14) e Produtos Alimentares (16) (tabelas 1 e 2).

É interessante salientar que o setor Indústria Têxtil (14) permaneceu como setor-chave para todas as regiões no período analisado. Outro ponto que merece destaque é a tendência de redução do número de setores-chave quando as regiões são analisadas isoladamente. Em 1985 foram detectados 16 setores-chave nas regiões brasileiras ao passo que em 1995 foram 12, fato que pode estar indicando maior integração entre as regiões e o exterior. Neste caso, a conseqüência é a perda relativa de importância dos setores locais enquanto fornecedores e demandantes de insumos. 
Tabela 1

Ligações de Rasmussen/Hirschman, grandes regiões, Brasil, 1985

\begin{tabular}{|c|c|c|c|c|c|c|c|c|c|c|c|c|c|c|c|c|c|c|c|c|}
\hline \multirow{2}{*}{$\begin{array}{l}\text { Regiões e } \\
\text { Setores }\end{array}$} & \multicolumn{4}{|c|}{ Norte } & \multicolumn{4}{|c|}{ Nordeste } & \multicolumn{4}{|c|}{ Centro-Oeste } & \multicolumn{4}{|c|}{ Sudeste } & \multicolumn{4}{|c|}{$\mathrm{S}$} \\
\hline & Frente & Rank & Trás & Rank & Frente & Rank & Trás & Rank & Frente & Rank & Trás & Rank & Frente & Rank & Trás & Rank & Frente & Rank & Trás & Rank \\
\hline 1. Agropecuária & 2,171 & 1 & 0,91 & 16 & 1,509 & 2 & 0,828 & 18 & 1,278 & 4 & 0,992 & 10 & 1,047 & 6 & 0,816 & 20 & 1,188 & 5 & $5 \quad 0,954$ & 14 \\
\hline 2. Mineração & 0,886 & 11 & 0,773 & 22 & 1,242 & 6 & 0,72 & 22 & 0,874 & 10 & 0,976 & 12 & 0,865 & 12 & 0,922 & 17 & 0,809 & 14 & $4 \quad 0,915$ & 19 \\
\hline 3. Minerais não Metálicos & 0,793 & 18 & 0,998 & 9 & 0,818 & 13 & 1,091 & 8 & 1,144 & 6 & 1,194 & 2 & 0,83 & 14 & 1,071 & 6 & 0,963 & 12 & 21,063 & 7 \\
\hline 4. Metalurgia & 0,893 & 10 & 0,947 & 14 & 1,458 & 3 & 1,25 & 2 & 1,067 & 8 & 0,94 & 15 & 2,122 & 2 & 1,255 & 1 & 1,455 & & 1,051 & 8 \\
\hline 5. Mecânica & 0,971 & 8 & 1,064 & 7 & 0,912 & 10 & 1,036 & 9 & 0,746 & 16 & 0,906 & 19 & 1,002 & 8 & 1,042 & 11 & 1,058 & 9 & 0,933 & 17 \\
\hline 6. Material Elétrico & 0,868 & 12 & 0,887 & 17 & 0,771 & 14 & 0,971 & 13 & 0,744 & 17 & 0,961 & 14 & 0,722 & 17 & 1,053 & 8 & 0,732 & 18 & 0,942 & 16 \\
\hline 7. Material de Transporte & 0,849 & 13 & 1,055 & 8 & 0,663 & 21 & 0,901 & 15 & 0,722 & 20 & 0,907 & 18 & 0,975 & 10 & 1,241 & 2 & 0,717 & 19 & $9 \quad \mathbf{1 , 0 9}$ & 5 \\
\hline 8. Madeira e Mobiliário & 0,808 & 17 & 1,122 & 5 & 0,704 & 17 & 0,954 & 14 & 0,793 & 14 & 1,066 & 5 & 0,643 & 19 & 0,985 & 13 & 0,849 & 13 & 1,1 & 4 \\
\hline 9. Celulose, Papel e Gráfica & 0,78 & 20 & 1,187 & 3 & 1,049 & 9 & 1,092 & 7 & 0,831 & 12 & 0,99 & 11 & 0,97 & 11 & 1,051 & 9 & 1,043 & 11 & 1,08 & 6 \\
\hline 10. Indústria da Borracha & 0,809 & 16 & 1,171 & 4 & 0,726 & 16 & 1,165 & 5 & 0,752 & 15 & 0,887 & 20 & 0,831 & 13 & 1,076 & 5 & 0,806 & 15 & $5 \quad 0,964$ & 12 \\
\hline 11. Química & 0,943 & 9 & 0,887 & 18 & 2,009 & 1 & 1,244 & 3 & 0,927 & 9 & 0,878 & 21 & 2,264 & 1 & 0,938 & 16 & 1,79 & 1 & $1 \quad 0,889$ & 20 \\
\hline 12. Farmacêutica & 0,718 & 22 & 0,976 & 11 & 0,651 & 22 & 1,027 & 10 & 0,716 & 21 & 1,002 & 9 & 0,566 & 22 & 0,947 & 15 & 0,632 & 22 & 20,978 & 11 \\
\hline 13. Plásticos & 0,789 & 19 & 0,844 & 21 & 0,685 & 19 & 1,155 & 6 & 0,738 & 18 & 0,873 & 22 & 0,722 & 16 & 1,026 & 12 & 0,773 & 16 & 0,986 & 10 \\
\hline 14. Indústria Têxti & 1,194 & 4 & 1,108 & 6 & 1,084 & 8 & 1,278 & 1 & 1,075 & 7 & 1,032 & 7 & 1,21 & & 1,109 & 3 & 1,156 & & 1,122 & 3 \\
\hline 15. Vestuário e Calçados & 0,729 & 21 & 1,231 & 2 & 0,677 & 20 & 0,986 & 12 & 0,735 & 19 & 1,005 & 8 & 0,582 & 21 & 1,081 & 4 & 0,746 & 17 & 71,135 & 2 \\
\hline 16. Produtos Alim & 0,99 & 7 & 1,296 & 1 & 0,868 & 11 & 1,194 & 4 & 0,865 & 11 & 1,353 & 1 & 0,752 & 15 & 1,051 & 10 & 1,046 & 10 & 1,31 & 1 \\
\hline 17. Indústrias Dive & 0,824 & 15 & 0,96 & 12 & 0,764 & 15 & 0,73 & 21 & 0,715 & 22 & 1,033 & 6 & 0,657 & 18 & 0,953 & 14 & 0,693 & 21 & 10,931 & 18 \\
\hline 18. SIUP & 0,994 & 6 & 0,979 & 10 & 1,156 & 7 & 1,006 & 11 & 1,334 & 3 & 1,092 & 4 & 1,002 & 9 & 0,88 & 19 & 1,146 & 7 & $7 \quad 0,961$ & 13 \\
\hline 19. Construção Civi & 0,835 & 14 & 0,916 & 15 & 0,689 & 18 & 0,888 & 16 & 0,811 & 13 & 1,097 & 3 & 0,619 & 20 & 1,055 & 7 & 0,71 & 20 & 1,002 & 9 \\
\hline 20. Comércio & 1,473 & 3 & 0,952 & 13 & 1,376 & 4 & 0,776 & 20 & 1,606 & 2 & 0,939 & 16 & 1,191 & 5 & 0,79 & 21 & 1,342 & 3 & $\begin{array}{ll}0,838 \\
\end{array}$ & 21 \\
\hline 21. Transportes & 1,153 & 5 & 0,885 & 19 & 0,832 & 12 & 0,886 & 17 & 1,255 & 5 & 0,962 & 13 & 1,026 & 7 & 0,919 & 18 & 1,107 & 8 & $3 \quad 0,943$ & 15 \\
\hline 22. Serviços & 1,531 & 2 & 0,853 & 20 & 1,357 & 5 & 0,823 & 19 & 2,273 & 1 & 0,918 & 17 & 1,404 & 3 & 0,743 & 22 & 1,238 & 4 & $\begin{array}{l}4 \quad 0,813 \\
\end{array}$ & 22 \\
\hline
\end{tabular}

Fonte: Cálculos dos autores. 
Tabela 2

Ligações de Rasmussen/Hirschman, grandes regiões, Brasil, 1995

\begin{tabular}{|c|c|c|c|c|c|c|c|c|c|c|c|c|c|c|c|c|c|c|c|c|}
\hline \multirow{2}{*}{$\begin{array}{l}\text { Regiões e } \\
\text { Setores }\end{array}$} & \multicolumn{4}{|c|}{ Norte } & \multicolumn{4}{|c|}{ Nordeste } & \multicolumn{4}{|c|}{ Centro-Oeste } & \multicolumn{4}{|c|}{ Sudeste } & \multicolumn{4}{|c|}{ Sul } \\
\hline & Frente & Rank & Trás & Rank & Frente & Rank & Trás & Rank & Frente & Rank & Trás & Rank & Frente & Rank & Trás & Rank & Frente & e Rank & Trás & Rank \\
\hline 1. Agropecuária & 1,762 & 1 & 0,877 & 17 & 1,494 & 3 & 0,815 & 18 & 1,486 & & $\longdiv { 1 , 0 0 6 }$ & 9 & 1,08 & 8 & 0,814 & 20 & 1,401 & 1 & 0,98 & 10 \\
\hline 2. Mineração & 0,848 & 11 & 0,819 & 22 & 0,924 & 9 & 0,785 & 21 & 0,869 & 10 & 1,116 & 2 & 0,766 & 16 & 1,116 & 5 & 0,767 & 17 & 1,055 & 7 \\
\hline 3. Minerais não Metálicos & 0,767 & 19 & 0,933 & 13 & 0,834 & 12 & 1,048 & 11 & 0,836 & 13 & 1,099 & 3 & 0,953 & 10 & 1,067 & 8 & 0,923 & 12 & 1,02 & 8 \\
\hline 4. Metalurgia & 0,892 & 10 & 0,942 & 12 & 1,286 & 6 & 1,217 & 2 & 0,844 & 12 & 0,921 & 18 & 1,925 & 2 & 1,225 & 1 & 1,211 & 7 & 1,009 & 9 \\
\hline 5. Mecânica & 0,954 & 8 & 1,021 & 8 & 0,878 & 10 & 1,056 & 9 & 0,714 & 17 & 0,852 & 22 & 0,881 & 11 & 0,951 & 15 & 1,117 & 8 & 0,861 & 21 \\
\hline 6. Material Elétrico & 0,824 & 14 & 0,849 & 19 & 0,824 & 14 & 0,98 & 12 & 0,708 & 18 & $3 \quad 0,934$ & 16 & 0,7 & 17 & 1,056 & 9 & 0,729 & 19 & 0,946 & 14 \\
\hline 7. Material de Trans & 0,773 & 18 & 1,002 & 9 & 0,666 & 20 & 0,917 & 14 & 0,704 & 19 & 0,866 & 21 & 0,859 & 13 & 1,187 & 2 & 0,725 & 20 & 1,061 & 6 \\
\hline 8. Madeira e Mobiliário & 0,773 & 17 & 1,128 & 6 & 0,715 & 16 & 0,945 & 13 & 0,749 & 15 & 1,078 & 5 & 0,677 & 18 & 0,994 & 12 & 0,87 & 13 & 1,13 & 5 \\
\hline 9. Celulose, Papel e Gráfica & 0,797 & 15 & 1,239 & 3 & 0,983 & 8 & 1,159 & 5 & 0,915 & 9 & 1,082 & 4 & 0,978 & 9 & 1,117 & 4 & 1,048 & 10 & 1,131 & 4 \\
\hline 10. Indústria da Borracha & 0,836 & 13 & 1,246 & 2 & 0,719 & 15 & 1,195 & 4 & 0,775 & 14 & $4 \quad 0,942$ & 13 & 0,866 & 12 & 1,098 & 7 & 0,815 & 14 & 0,97 & 12 \\
\hline 11. Química & 1,524 & 3 & 0,868 & 18 & 2,149 & 1 & 1,198 & 3 & 1,57 & 2 & 0,937 & 15 & 2,211 & 1 & 0,965 & 14 & 1,383 & 3 & 0,898 & 17 \\
\hline 12. Farmacêutica & 0,704 & 22 & 0,954 & 11 & 0,642 & 22 & 1,089 & 8 & 0,697 & 22 & 0,997 & 10 & 0,573 & 22 & 0,924 & 16 & 0,654 & 22 & 0,973 & 11 \\
\hline 13. Plásticos & 0,714 & 21 & 0,905 & 15 & 0,669 & 19 & 1,113 & 7 & 0,698 & 21 & 0,904 & 20 & 0,797 & 15 & 0,992 & 13 & 0,798 & 15 & 0,94 & 15 \\
\hline 14. Indústria Têxti & 1,441 & 4 & 1,164 & 5 & 1,054 & 7 & 1,32 & 1 & 1,167 & & 1,074 & 6 & 1,165 & & 1,102 & 6 & 1,226 & 6 & 1,141 & 3 \\
\hline 15. Vest & 0,722 & 20 & 1,292 & 1 & 0,69 & 18 & 1,056 & 10 & 0,723 & 16 & 1,074 & 7 & \begin{tabular}{l|l} 
& 0,599
\end{tabular} & 21 & 1,117 & 3 & 0,745 & 18 & 1,185 & 2 \\
\hline 16. Produ & 0,971 & 7 & 1,229 & 4 & 0,858 & 11 & 1,151 & 6 & 0,916 & 8 & 1,365 & 1 & 0,82 & 14 & 1,051 & 10 & 1,014 & 11 & 1,334 & 1 \\
\hline 17. Indústrias Div & 0,929 & 9 & 1,078 & 7 & 0,651 & 21 & 0,76 & 22 & 0,702 & 20 & 1,039 & 8 & 0,651 & 19 & 1,008 & 11 & 0,705 & 21 & 0,961 & 13 \\
\hline 18. SIUP e Comunicações & 1,196 & 6 & 0,922 & 14 & 1,414 & 5 & 0,916 & 15 & 1,126 & 6 & 0,951 & 12 & 1,094 & 6 & 0,795 & 21 & 1,336 & 4 & 0,885 & 19 \\
\hline 19. Construção Civi & 0,779 & 16 & 0,823 & 21 & 0,696 & 17 & 0,796 & 20 & 0,847 & 11 & 0,933 & 17 & 0,617 & 20 & 0,906 & 17 & 0,774 & 16 & 0,896 & 18 \\
\hline 20. Comércio & 1,391 & 5 & 0,976 & 10 & 1,58 & 2 & 0,803 & 19 & 1,164 & 5 & 0,983 & 11 & 1,107 & 5 & 0,865 & 19 & 1,249 & 5 & 0,882 & 20 \\
\hline 21. Transportes & 0,84 & 12 & 0,89 & 16 & 0,832 & 13 & 0,854 & 16 & 1,028 & 7 & 0,94 & 14 & 1,087 & 7 & 0,897 & 18 & 1,112 & 9 & 0,915 & 16 \\
\hline 22. Serv & 1,565 & 2 & 0,844 & 20 & 1,44 & 4 & 0,828 & 17 & 2,763 & 1 & 0,909 & 19 & 1,597 & 3 & 0,756 & 22 & 1,397 & 2 & 0,826 & 22 \\
\hline
\end{tabular}

Fonte: Cálculos dos autores. 
As tabelas 3 e 4 apresentam os índices de ligações para o sistema inter-regional. A partir das informações nelas contidas, pode-se resumir e padronizar os índices para frente e para trás de cada região e, assim, evidenciar o grau de ligações inter-regionais de cada uma e a evolução dessas ligações no tempo, o que pode ser visualizado nas figuras 1 e 2 .

Desse modo, tanto para 1985 quanto para 1995, dois padrões distintos emergem dentro da economia nacional regionalizada: a) uma região com estrutura setorial melhor articulada, Sudeste; e b) regiões que ainda buscam implementar e consolidar sua estrutura produtiva, Nordeste, Sul, Norte e Centro-Oeste (figuras 1 e 2).

O Sudeste apresentou maiores índices de ligações para frente e para trás relativamente à média dos setores das grandes regiões brasileiras, revelando que suas relações econômicas de compra e venda estão melhor articuladas com os mercados regional e inter-regional, embora se perceba redução na magnitude dos índices de ligações para frente de 1985 para 1995 (tabelas 3 e 4 e figuras 1 e 2).

Contrariamente, as regiões Nordeste, Sul, Norte e Centro-Oeste desenham padrões típicos de ligações frágeis entre os setores, tanto no aspecto domésticos quanto no inter-regional, refletidos nos baixos índices médios para frente, que se situam entre 0,73 e 0,93, e nos baixos índices médios para trás, que oscilam entre 0,92 e 1,04 para ambos os anos em tela. No entanto, vale destacar que esses índices apresentaram tendência de crescimento entre 1985 e 1995 para as regiões Norte, Nordeste e Centro-Oeste (tabelas 3 e 4).

É interessante apontar, no que se refere aos índices de ligações para trás, que, embora o Sudeste tenha se destacado, manteve o padrão verificado para as outras 4 regiões, ou seja, tanto quanto o Nordeste, o Sul, o Norte e o Centro-Oeste, o Sudeste depende das demais regiões para o abastecimento de seu mercado interno no que se refere a compra de insumos para o processo produtivo (tabelas 3 e 4 e figuras 1 e 2 ).

A partir do critério restrito para a determinação dos setores-chave, estabelecido por McGilvray (1977) e especificados acima, as informações das figuras 1 e 2, conjugadas com as informações mais detalhadas dos padrões de ligações intersetoriais e de como elas variam no espaço e no tempo (tabelas 3 e 4), sugerem algumas orientações importantes para o estabelecimento de políticas de promoção setorial em cada região. 
Tabela 3

Ligações de Rasmussen/Hirschman, sistema inter-regional, Brasil, 1985

\begin{tabular}{|c|c|c|c|c|c|c|c|c|c|c|c|c|c|c|c|c|c|c|c|c|}
\hline Setores & \multicolumn{4}{|c|}{ Norte } & \multicolumn{4}{|c|}{ Nordeste } & \multicolumn{4}{|c|}{ Centro-Oeste } & \multicolumn{4}{|c|}{ Sudeste } & \multicolumn{4}{|c|}{ Sul } \\
\hline 2. Mineração & 0,815 & 51 & 0,573 & 110 & 1,364 & 19 & 0,601 & 109 & 0,668 & 67 & 0,898 & 83 & 1,599 & 12 & 0,917 & 76 & 0,713 & 58 & 0,923 & 75 \\
\hline 3. Mine & 0,566 & 92 & 0,818 & 95 & 0,663 & 70 & 0,972 & 64 & 0,844 & 48 & 1,084 & 36 & 1,117 & 30 & 1,1 & 30 & 0,828 & 50 & 1,112 & 26 \\
\hline $\mathrm{n}$ & 0,7 & 61 & 1,12 & 23 & 0,765 & 55 & & 1 & 0,528 & 100 & 1,029 & 56 & 1,877 & 7 & 1,039 & 55 & 0,999 & 38 & 1,049 & 53 \\
\hline 6. $\mathrm{M}$ & 0,694 & 64 & 0,833 & 94 & 0,634 & 74 & 0,947 & 68 & 0,528 & 101 & 1,066 & 45 & 1,159 & 26 & 1,072 & 40 & 0,632 & 75 & 1,089 & 33 \\
\hline $\mathrm{M}$ & 0,622 & 78 & 1,211 & 12 & & 90 & & 25 & 0,511 & 66 & & 10 & 1,843 & 8 & & 8 & 0,6 & 79 & 1,195 & 14 \\
\hline 8. $\mathrm{M}$ & & 82 & 0,891 & 84 & & 93 & & 79 & 0,563 & 94 & & 0 & 0,6 & 65 & & 39 & 0,7 & 52 & 1,087 & 34 \\
\hline 9. $\mathrm{C}$ & 0,554 & 96 & 1,064 & 47 & & 46 & & 41 & 0 & 5 & & 54 & 1, & 3 & & 48 & 0, & 43 & 1,065 & 46 \\
\hline 12. $\mathrm{F}$ & 0,503 & & & 1 & & 102 & & & & 8 & & 5 & 0,7 & 53 & & 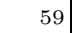 & & 105 & 0,999 & 58 \\
\hline 13. $\mathrm{I}$ & 0,554 & 95 & 0,93 & 72 & & 91 & & 52 & & 103 & & 5 & & 42 & & 32 & 0 & 69 & 4 & 31 \\
\hline 14. I & & 9 & 0,942 & 69 & & & & 1 & 0,7 & 56 & & 6 & & 5 & & 15 & & 35 & & 18 \\
\hline 15. & & 107 & 1,084 & 37 & & 98 & & 49 & & 104 & & 22 & & 81 & & 20 & & 72 & 1 , & 21 \\
\hline 16. $\mathrm{I}$ & 0,7 & & & & & 7 & & 28 & & 77 & & 1 & & ) & & & & 28 & & \\
\hline 17. I & & 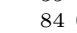 & 0,8 & 93 & & 73 & & 108 & & 109 & & 67 & & 45 & & 61 & & 8 & 0 , & 60 \\
\hline 18. & & ) & & 0 & & 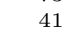 & & 85 & & . & & 90 & & 20 & & 88 & & 4 & & 87 \\
\hline 19. & & 6 & & 4 & & 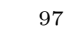 & & 92 & & & & 51 & & 71 & & 42 & & 7 & & 38 \\
\hline
\end{tabular}

Fonte: Cálculos dos autores. 
Tabela 4

Ligações de Rasmussen/Hirschman, sistema inter-regional, Brasil, 1995

\begin{tabular}{|c|c|c|c|c|c|c|c|c|c|c|c|c|c|c|c|c|c|c|c|c|}
\hline Setores & \multicolumn{4}{|c|}{ Norte } & \multicolumn{4}{|c|}{ Nordeste } & \multicolumn{4}{|c|}{ Centro-Oeste } & \multicolumn{4}{|c|}{ Sudeste } & \multicolumn{4}{|c|}{ Sul } \\
\hline 2. Mineraçã & 0,822 & 50 & 0,672 & 109 & 0,933 & 44 & 0,698 & 107 & 0,726 & 61 & 1,097 & 38 & 1,165 & 30 & 1,12 & 32 & 0,663 & 72 & 1,123 & 31 \\
\hline 3. Mine & 0,594 & 91 & 0,798 & 94 & 0,709 & 66 & 0,952 & 66 & 0,654 & 75 & 1,06 & 46 & 1,268 & 25 & 1,085 & 41 & 0,79 & 53 & 1,085 & 42 \\
\hline 5. Mecấ & 0,744 & 58 & 0,989 & 59 & 0,766 & 54 & 1,221 & 10 & 0,551 & 99 & 0,939 & 72 & 1,352 & 19 & 0,944 & 70 & 1,04 & $40 \mathrm{c}$ & 0,942 & 71 \\
\hline 6. $\mathrm{Ma}$ & & 69 & & 95 & & 64 & & 64 & 0,546 & 102 & 1,06 & 47 & 0,991 & 42 & 1,071 & 44 & 0,627 & 80 & 1,075 & 43 \\
\hline 7. $\mathrm{M}$ & 0 , & 86 & 1,0 & 40 & & 93 & & 34 & 542 & 104 & & 20 & & 18 & & 13 & 0,624 & 81 & & 24 \\
\hline 8. $\mathrm{N}$ & & 85 & 0,951 & 67 & & 87 & & 69 & 0,578 & 96 & & 5 & & 7 & & 7 & & 52 & & 39 \\
\hline 9. $\mathrm{C}$ & 0 & 82 & 1,13 & 28 & & 49 & 1, & 12 & 11 & 5 & & 29 & 1,4 & 13 & & 27 & 0,9 & 43 & 1, & 30 \\
\hline 12. $\mathrm{I}$ & & 109 & & 73 & & 105 & & 3 & & & & 5 & & 83 & & 2 & & 106 & & 63 \\
\hline 13. $\mathrm{P}$ & & 103 & 0,868 & 85 & & 97 & 1,034 & 54 & & 108 & & 50 & 1 & 38 & 1 & 48 & 0,692 & 70 & 1,046 & 51 \\
\hline 14. I & & 34 & & 60 & & & & 2 & & 47 & & 1 & & 6 & & 14 & & 32 & & 15 \\
\hline 15. Ves & & 100 & & 26 & & 95 & & 18 & & 8 & & 16 & 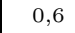 & 89 & & 17 & 0,6 & 78 & 1,17 & 19 \\
\hline 16. I & & & & & & 5 & & 35 & & 9 & & 8 & 1,0 & 9 & & 1 & & 36 & & \\
\hline 17. I & & ( & 0,9 & 61 & & 101 & 0,66 & 110 & 0,54 & 107 & 1, & 55 & 0,7 & 55 & & 52 & 0,5 & 92 & 1, & 53 \\
\hline 18. & & & & & & & & 93 & & 18 & & & & & & & & 26 & & \\
\hline 19. & & 90 & & 4 & & 94 & & 105 & 0,658 & 3 & & 81 & & 9 & & 77 & & 7 & & 78 \\
\hline
\end{tabular}

Fonte: Cálculos dos autores. 
Figura 1

Padrão médio dos índices de ligações de Rasmussen-Hirschman para as grandes regiões brasileiras, 1985

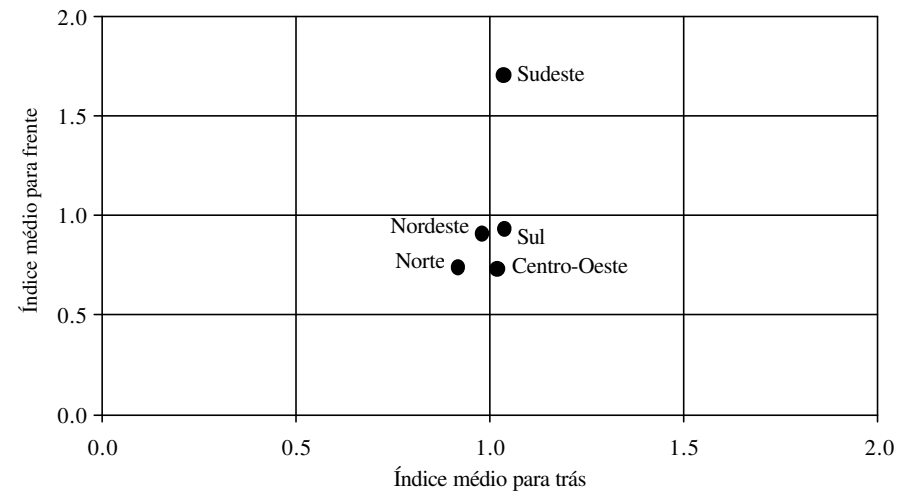

Fonte: tabela 5 .

Figura 2

Padrão médio dos Índices de ligações de Rasmussen-Hirschman para as grandes regiões brasileiras, 1995

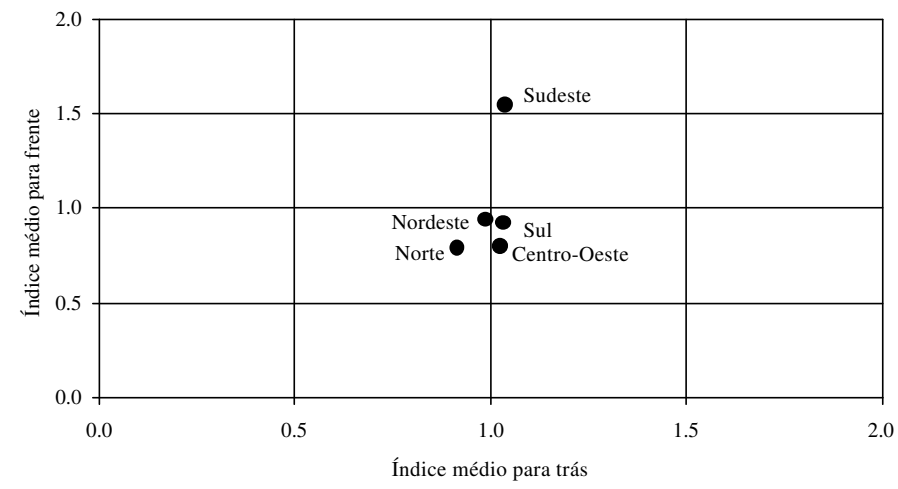

Fonte: tabela 4 .

Para a região Sudeste, os resultados sugerem que seria mais adequado adotar políticas específicas para os setores-chave que apresentaram grandes ligações para frente do que para os que apresentaram grandes ligações para trás, uma vez que as primeiras $(1,70$ e 1,55) foram superiores às últimas $(1,04)$ para 1985 e 1995, 
respectivamente. Assim, dos oito setores-chave em 1985 (3, 4, 5, 6, 7, 9, 10, 14) e dos dez em 1995 (2, 3, 4, 7, 9, 10, 11, 13, 14, 16), as políticas que priorizarem os setores Metalurgia, Mecânica, Material de Transporte, Celulose, Papel e Gráfica, Química e Indústria Têxtil serão altamente desejáveis.

Na perspectiva menos restrita de Rasmussen (1956) e Hirschman (1958), maior número de setores-chave podem ser incluídos para se delinear, de forma mais completa e clara, o perfil das relações inter-regionais. Desse modo, 'relaxando' o conceito de setores-chave, a região Sudeste apresentou para 1985 e 1995, além dos 8 e 10 setores-chave detectados no critério restrito, 12 setores-chave $(7$ com ligações para frente e 5 com ligações para trás) e 10 setores-chave (6 com ligações para frente e 4 com ligações para trás), respectivamente (tabelas 3 e 4).

Como corolário da análise dos índices de ligação de Rasmussen/Hirschman, considerando o sistema inter-regional, pode-se apontar as seguintes características da economia do Sudeste no período: a) a conjugação de índices de ligações para trás elevados para a maioria dos setores do ramo secundário, a exemplo de Metalurgia, Material de Transporte, Produtos Alimentares, etc., com índices de ligações para frente mais elevados ainda em setores como Metalurgia, Química, Indústria Têxtil, Serviços, dentre outros, mostra que o Sudeste possui indústria diversificada, centrada nas indústrias produtoras de matérias primas e nas indústrias de transformação; b) o Sudeste é a única região que apresentou média dos índices para frente maior do que a dos índices para trás, revelando a importância de seus setores como fornecedores às demais regiões; c) embora o número de setores-chave com ligações para frente tenha sido pouco maior do que o número de setoreschave com ligações para trás por ambos os critérios, pode-se afirmar que políticas que incentivem a oferta de insumos intermediários serão bem-vindas, d) o setor serviços se desponta como grande ofertante dentro do sistema inter-regional; e) de forma geral, os índices de ligações para frente revelaram queda da participação dos setores desta região na atividade econômica nacional devido à redução de suas médias entre os anos em tela, indicando que a região Sudeste tende a enfrentar diversificação dos concorrentes no que se refere à oferta de insumos inter-regional, o que reforça a sugestão feita no item c; d) mesmo assim, o Sudeste, se manteve como pólo dinâmico da economia brasileira nesses dez anos, especialmente no que se refere à indústria de transformação, com a média de seus índices para frente e para trás maior do que a das outras regiões, revelando, em função de sua melhor articulação industrial, mais capacidade para induzir, dentro do Brasil, a integração dos mercados. 
O padrão de ligações fracas apresentado pelas regiões Sul, Nordeste, Norte e Centro-Oeste, como salientado anteriormente, deve ser detalhadamente analisado, uma vez que importantes diferenças existem entre esse grupo de economias.

Uma característica comum a essas regiões é que todas elas apresentaram as ligações médias para trás maiores do que as ligações médias para frente, exatamente o contrário do que ocorreu para a região Sudeste (tabelas 3 e 4 e figuras 1 e 2). Isso permite sugerir que os setores-chave dessas regiões despontam como os mais indicados para serem alvos de políticas de crescimento/desenvolvimento industrial que estimulem a demanda por insumos intermediários, notadamente se essa demanda for atendida por insumos da região e, no contexto inter-regional, por insumos nacionais.

Considerando as regiões separadamente, observa-se, pelas tabelas 3 e 4, que a região Sul apresentou, respectivamente, 4 e 3 setores-chave em 1985 e 1995 no critério restrito e que as ligações médias para trás (1,04 e 1,03) predominaram sobre as ligações médias para frente (0,93 e 0,92), respectivamente em 1985 e 1995, apontando os setores Metalurgia, Indústria Têxtil e Produtos Alimentares, com maior poder de ligações para trás, como os prioritários para políticas de crescimento industrial.

Na região Nordeste, 3 setores-chave foram detectados para ambos os anos estudados, e as ligações médias para trás $(0,98$ e 0,99) apresentaram-se ligeiramente superiores às ligações médias para frente $(0,91$ e 0,94) para 1985 e 1995, respectivamente (tabelas 3 e 4 e figuras 1 e 2). Observou-se tendência de crescimento de ambas as ligações no período, o que aponta na direção de possível emergência de novos setores importantes para a região e reforça a recomendação de que os setores Metalurgia, Química e Indústria Têxtil, além de outros setores-chave na hipótese de relaxamento, a exemplo de Mecânica, Material de Transporte, Celulose, Papel e Gráfica, Indústria da Borracha, Farmacêutica, Plásticos, Vestuário e Calçados e Produtos Alimentares, devem ser priorizados no caso de políticas de crescimento industrial.

As regiões Norte e Centro-Oeste não apresentaram setores-chave quando considerado o sistema inter-regional e o critério restrito (tabelas 3 e 4). Mesmo assim, os índices médios de ligações para trás maiores do que os de ligações para frente sugerem que os setores Material de Transporte, Celulose, Papel e Gráfica, Vestuário e Calçados e Produtos Alimentares no Norte, e Minerais não Metálicos, Metalurgia, Material de Transporte, Madeira e Mobiliário, Celulose, Papel e Gráfica, Indústria da Borracha, Indústria Têxtil, Vestuário e Calçados, Produtos Alimentares, dentre outros, no Centro-Oeste, devem ser alvos prioritários de políticas de crescimento industrial. 
Ao se verificar o número de setores-chave com ligações para trás (critério restrito), nas quatro regiões para os dois anos em análise, 13 para a Sul, 13 para a Centro-Oeste, 11 para a Nordeste e 7 e 5 para a Norte em 1985 e 1995, respectivamente, (tabelas 3 e 4), observa-se que as regiões Sul e Centro-Oeste apresentaram índices médios de ligações maiores do que os das regiões Norte e Nordeste e que, em muitos casos, os setores-chave para as regiões coincidem, notadamente entre as duas primeiras regiões, indicando a semelhança da importância relativa das ligações para trás.

Considerando a hipótese menos restrita para a definição de setores-chave, as regiões apresentaram, além dos setores definidos como chave no critério restrito: Sul, 16 e 17 setores-chave para 1985 e 1995, respectivamente; Nordeste 12, CentroOeste 16 e Norte 9 e 10 para 1985 e 1995, respectivamente. O número de setoreschave com ligações para frente no Sul (10) e no Nordeste (7), para ambos os anos, é maior do que nas outras duas regiões. Além disso, a maioria desses setores coincide, revelando que estas regiões apresentam padrão semelhante, com poder de ligações para frente centrado na Agropecuária, Metalurgia, Química, Indústria Têxtil, Comércio e Serviços. A grande diferença é o setor Produtos Alimentares que foi chave para a região Sul e que apresentou, para ambos os anos, grande poder de ligação para frente.

As regiões Centro-Oeste e Norte desenham padrão distante em relação ao do Sul e Nordeste e próximos entre si, com poucos setores com ligações para frente (3 para o Centro-Oeste e 3 e 5 para o Norte, em 1985 e 1995, respectivamente), destacando-se a Agropecuária e Serviços (tabelas 3 e 4).

A análise inter-regional permite constatar que os baixos índices de ligações para frente de alguns setores básicos do segmento de transformação, a exemplo de Metalurgia, Mecânica, Material Elétrico e Material de Transporte, detectados para as quatro regiões, notadamente a Centro-Oeste e a Norte, apontam a falta de estrutura para a implantação de processo maior de industrialização, o que explica o padrão de fracas relações intersetoriais mostrados nas figuras 1 e 2 . Não obstante, vale salientar a tendência de aumento da participação dos setores dessas regiões na atividade econômica nacional, tendência esta revelada pelo crescimento da média dos índices de ligações, notadamente dos índices para frente entre 1985 e 1995 (tabelas 3 e 4). Este fato corrobora a indicação anterior de possível crescimento da interdependência entre as regiões brasileiras e o exterior, podendo auxiliar na redução das desigualdades regionais se conjugado com planejamento e políticas desenvolvimentistas de longo prazo. 
Em síntese, considerando os índices de ligações mostrados nas tabelas 3 e 4, pode-se determinar os setores com maior capacidade para dinamizar a economia nacional. Levando em consideração os 10 maiores índices de ligações para frente para os dois anos estudados, nota-se que a oferta de insumos para o processo produtivo se opera por meio dos setores 4, 5, 7, 11, 14, 20, e 22 do Sudeste; dos setores 1, 4, 11 e 20 do Nordeste; dos setores 1, 4, 11 e 20 do Sul, do setor 22 do Centro-Oeste e do setor 1 do Norte. De 1985 para 1995 o arranjo dos setores ofertantes apresenta mudanças importantes. No Sudeste ocorre a saída dos setores 5 e 7, no Nordeste a entrada do setor 20, no Sul a substituição do setor 11 pelo setor 1 e o Centro-Oeste se desponta com o setor 22 (tabelas 3 e 4). A partir dessas informações pode-se apontar algumas características da economia nacional regionalizada: dos 10 setores com maiores índices de ligações para frente, respectivamente, para 1985 e 1995, sete e cinco são da região Sudeste e, dentre eles, pelo menos quatro estão entre os seis que apresentaram os maiores índices para frente do sistema inter-regional; os setores Agropecuária, Química e Comércio se destacam enquanto dinamizadores das relações intersetoriais para frente em duas ou mais regiões no período; a tendência à diversificação da estrutura produtiva das regiões que apresentam setores com maiores ligações para frente de 1985 para 1995 .

Ainda levando em conta a economia nacional segmentada em regiões, dos 10 setores com maiores índices de ligações para trás em 1985, 3 estão no Sudeste (4, 7, 16), 3 fazem parte do Nordeste (4, 5, e 14), 2 do Centro-Oeste (4 e 7) e 2 do Sul (4 e 16). Para 1995, a situação foi a seguinte: o Sudeste apresentou 2 setores (4 e 16), o Nordeste 4 (4, 5, 10 e 14), o Centro-Oeste 2 (4 e 16) e o Sul 2 (4 e 16). Nota-se, assim, que a demanda por insumos para o processo produtivo está, relativamente, bem distribuída entre as regiões brasileiras, com forte concentração nos setores Metalurgia e Produtos Alimentares (tabelas 3 e 4). 


\section{2 Índices puros de ligações: abordagem GHS}

A abordagem GHS corrige a deficiência dos índices de ligações de RasmussenHirschman ao medir a importância de dado setor para a economia em termos do seu valor da produção. Assim, o método de apuração de índices puros permite calcular as ligações para frente, que mostram o impacto puro da produção total do restante da economia em determinado setor/região, e as ligações para trás, que revelam o impacto puro do valor da produção total de determinado setor/região no restante da economia. Os setores que apresentam o índice puro total normalizado (PTLN) maior do que 1 são considerados chave, pois foram os setores que tiveram o índice puro total (PTL) maior do que a média da região.

As tabelas 5 e 6 apresentam os índices de ligações normalizados para frente (PFLN), para trás (PBLN) e total (PTLN) para as cinco regiões brasileiras nos anos de 1985 e 1995, respectivamente. Pode-se observar claramente o domínio da região Sudeste, que apresentou os mesmos 9 setores-chave para 1985 e 1995, Agropecuária (1), Metalurgia (4), Material de Transporte (7), Química (11), Produtos Alimentares (16), Construção Civil (19), Comércio (20), Transportes (21) e Serviços (22).

No Sudeste, os setores que mais se destacaram nas ligações para frente nos anos em tela foram Agropecuária (1), Metalurgia (4), Química (11), Comércio (20), Transportes (21) e Serviços (22), ou seja, esses setores foram os mais impactados pela produção total do restante da economia do Sudeste. Por outro lado, os setores que mais impactaram o restante da economia em 1985 foram Material Elétrico (6), Material de Transporte (7), Química (11), Vestuário e Calçados (15), Produtos Alimentares (16), Construção Civil (19), Comércio (20), e Serviços (22), ao passo que, em 1995, perdem importâncias os setores Química (11) e Vestuário e Calçados (15) (tabelas 5 e 6$)$.

Todas as outras regiões apresentaram número parecido de setores-chave em ambos os anos analisados. As regiões Centro-Oeste e Sul reduziram seus setores de 7 para 6, enquanto as regiões Norte e Nordeste mantiveram 7 setores-chave em 1985 e 1995, respectivamente. Embora tenham ocorrido algumas mudanças na combinação dos setores-chave destas 4 regiões nos anos em tela, não se constatou grandes alterações nas estruturas setoriais das economias regionais no que se refere aos índices puros, vale dizer, ao valor da produção.

A visão geral das tabelas 5 e 6 permite apontar os setores Agropecuária (1), Produtos Alimentares (16), Construção Civil (19), Comércio (20) e Serviços (22) como os mais dinâmicos em todas as regiões em 1985, enquanto para 1995, além destes, acrescenta-se o setor Química (11). 
Tabela 5

Índices Puros para Frente (PFLN), Trás (PBLN) e Total (PTLN) Normalizados, grandes regiões, Brasil, 1985

\begin{tabular}{|c|c|c|c|c|c|c|c|c|c|c|c|c|c|c|c|}
\hline \multirow{2}{*}{$\begin{array}{l}\text { Regiões e } \\
\text { Setores }\end{array}$} & \multicolumn{3}{|c|}{ Norte } & \multicolumn{3}{|c|}{ Nordeste } & \multicolumn{3}{|c|}{ Centro-Oeste } & \multicolumn{3}{|c|}{ Sudeste } & \multicolumn{3}{|c|}{ Sul } \\
\hline & PFLN & PBLN & PTLN & PFLN & & PTLN & PFLN & PBLN & PTLN & PFLN & & PTLN & PFLI & PBLN & TLN \\
\hline 1. Agropecuária & 3,84 & 2,97 & 3,4 & 4,53 & 1,26 & 2,9 & 2,85 & 3,8 & 3,32 & 1,68 & 0,51 & 1,09 & 4,4 & 1,46 & 2,93 \\
\hline 2. Mineração & 0,69 & 0,52 & 0,61 & 2,32 & 0,16 & 1,24 & 0,37 & 0,48 & 0,42 & 0,81 & 0,23 & 0,52 & 0,37 & 0,04 & 0,21 \\
\hline 3. Minerais não Metálicos & 0,86 & 0,16 & 0,51 & 0,74 & 0,05 & 0,39 & 1,18 & 0,47 & 0,83 & 0,71 & 0,23 & 0,47 & 0,63 & 0,13 & 0,38 \\
\hline 4. Metalurgia & 0,76 & 0,08 & 0,42 & 0,84 & 0,47 & 0,66 & 0,54 & 0,11 & 0,32 & 3,18 & 0,86 & 2,02 & 1,15 & 0,12 & 0,63 \\
\hline 5. Mecânica & 0,64 & 0,16 & 0,4 & 0,47 & 0,11 & 0,29 & 0,06 & 0,04 & 0,05 & 0,94 & 0,91 & 0,92 & 0,72 & 0,43 & 0,57 \\
\hline 6. Material Elétrico & 0,22 & 1,13 & 0,68 & 0,15 & 0,19 & 0,17 & 0,09 & 0,11 & 0,1 & 0,44 & 1,1 & 0,77 & 0,2 & 0,31 & 0,25 \\
\hline 7. Material d & 0,07 & 0,39 & 0,23 & 0,08 & 0,05 & 0,06 & 0,03 & 0,02 & 0,03 & 0,85 & 1,7 & 1,28 & 0,18 & 0,38 & 0,28 \\
\hline 8. Madeira e Mobili & 0,67 & 1,48 & 1,08 & 0,19 & 0,12 & 0,15 & 0,15 & 0,26 & 0,2 & 0,2 & 0,25 & 0,23 & 0,29 & 0,82 & 0,55 \\
\hline 9. Celulose, Papel e & 0,18 & 0,48 & 0,33 & 0,6 & 0,04 & 0,32 & 0,37 & 0,05 & 0,21 & 0,98 & 0,28 & 0,63 & 1,01 & 0,17 & 0,59 \\
\hline 10. Indústria da $B$ & 0,24 & 0,28 & 0,26 & 0,06 & 0,03 & 0,05 & 0,05 & 0 & 0,03 & 0,44 & 0,1 & 0,27 & 0,23 & 0,02 & 0,13 \\
\hline 11. Química & 0,83 & 0,08 & 0,46 & 2,8 & 2,91 & 2,86 & 0,95 & 0,14 & 0,54 & 3,25 & 1,29 & 2,27 & 2,97 & 0,46 & 1,72 \\
\hline 12. Farm & 0,01 & 0,06 & 0,04 & 0,04 & 0,18 & 0,11 & 0,02 & 0,06 & 0,04 & 0,1 & 0,57 & 0,34 & 0,02 & 0,08 & 0,05 \\
\hline 13. Plást & 0,34 & 0,02 & 0 , & 0,28 & 0,17 & 0,22 & 0,06 & 0,01 & 0,04 & 0,45 & 0,15 & 0,3 & 0,42 & 0,07 & 0,24 \\
\hline 14. Indús & 0,36 & 0,15 & 0,25 & 0,62 & 0,95 & 0,79 & 0,29 & 0,09 & 0,19 & 0,92 & 0,36 & 0,64 & 1,15 & 0,22 & 0,69 \\
\hline 15. Vest & 0,02 & 0,16 & & 0 , & 0,6 & 0,33 & 0,02 & 0,21 & 0,12 & 0,05 & & 0,65 & 0,12 & 2,05 & 1,09 \\
\hline 16. Prod & 0,6 & 3,19 & 1 & 0,66 & 5,17 & 2,92 & 0,9 & 4,36 & 2,63 & 0,56 & 2,22 & 1,39 & 0,94 & 8,5 & 4,72 \\
\hline 17. Indús & 0,24 & 0,2 & 0,22 & 0,4 & 0,01 & 0,21 & 0,01 & 0,01 & 0,01 & 0,33 & 0,19 & 0,26 & 0,16 & 0,07 & 0,11 \\
\hline 18. SIU & 1,5 & 0,21 & 0,85 & 1,54 & 0,15 & 0,84 & 1,81 & 0,51 & 1,16 & 0,98 & 0,2 & 0,59 & 1,09 & 0,25 & 0,67 \\
\hline 19. Cons & 0,82 & 4,71 & 2,77 & 0,57 & 3,62 & 2,1 & 0,52 & 2,98 & 1,75 & 0,3 & 3,36 & 1,83 & 0,27 & 1,56 & 0,91 \\
\hline 20. Comé & 3,23 & 1,66 & 2,45 & 2,55 & 0,77 & 1,66 & 3,71 & 2,97 & 3,34 & 1,83 & 1,41 & 1,62 & 2,47 & 1,41 & 1,94 \\
\hline 21. Tran & 2,44 & 0,81 & 1,62 & 0,85 & 0,69 & 0,77 & 2,14 & 1 & 1,57 & 1,22 & 0,89 & 1,05 & 1,68 & 0,97 & 1,33 \\
\hline 22. Serviços & 3,43 & 3,09 & 3,26 & 1,66 & 4,29 & 2,97 & 5,88 & 4,32 & 5,1 & 1,78 & 3,95 & 2,87 & 1,53 & 2,48 & 2,01 \\
\hline
\end{tabular}


Tabela 6

Índices Puros para Frente (PFLN), Trás (PBLN) e Total (PTLN) Normalizados, grandes regiões, Brasil, 1995

\begin{tabular}{|c|c|c|c|c|c|c|c|c|c|c|c|c|c|c|c|}
\hline$\overline{\text { Regiões e }}$ & & Norte & & & Nordest & & & ntro-Oe & & & Sudeste & & & Sul & \\
\hline Setores & PFLN & PBLN & PTLN & PFLN & PBLN & PTLN & PFLN & PBLN & PTLN & PFLN & PBLN & PTLN & PFLN & PBLN & PTLN \\
\hline 1. Agropecuária & 3,12 & 1,61 & 2,36 & 3,46 & 1,04 & 2,25 & 3,89 & 2,97 & 3,43 & 1,97 & 0,47 & 1,22 & 4,87 & 1,34 & 3,11 \\
\hline 2. Mineração & 0,4 & 0,53 & 0,46 & 1 & 0,09 & 0,54 & 0,34 & 0,33 & 0,33 & 0,4 & 0,3 & 0,35 & 0,13 & 0,06 & 0,09 \\
\hline 3. Minerais não Metálicos & 0,55 & 0,12 & 0,33 & 0,93 & 0,08 & 0,51 & 0,75 & 0,13 & 0,44 & 0,79 & 0,22 & 0,5 & 0,75 & 0,09 & 0,42 \\
\hline 4. Metalurgia & 0,66 & 0,11 & 0,38 & 0,71 & 0,45 & 0,58 & 0,34 & 0,05 & 0,2 & 2,89 & 0,85 & 1,86 & 0,92 & 0,1 & 0,51 \\
\hline 5. Mecânica & 0,9 & 0,19 & 0,55 & 0,51 & 0,06 & 0,28 & 0,04 & 0,02 & 0,03 & 0,77 & 0,68 & 0,72 & 0,92 & 0,43 & 0,68 \\
\hline 6. Material Elétrico & 0,19 & 1,55 & 0,87 & 0,21 & 0,36 & 0,28 & 0,06 & 0,08 & 0,07 & 0,31 & 1,32 & 0,81 & 0,22 & 0,43 & 0,33 \\
\hline 7. Material de Trans 1 & 0,02 & 0,4 & 0,21 & 0,06 & 0,07 & 0,06 & 0,01 & 0,01 & 0,01 & 0,63 & 2,37 & 1,5 & 0,16 & 0,38 & 0,27 \\
\hline 8. Madeira e Mobiliário & 0,38 & 1,28 & 0,83 & 0,24 & 0,14 & 0,19 & 0,22 & 0,21 & 0,22 & 0,18 & 0,23 & 0,2 & 0,44 & 0,85 & 0,65 \\
\hline 9. Celulose, Papel e C & 0,3 & 1,27 & 0,78 & 0,45 & 0,03 & 0,24 & 0,6 & 0,1 & 0,35 & 1,05 & 0,35 & 0,7 & 0,96 & 0,19 & 0,58 \\
\hline 10. Indúst & 0,3 & 0,93 & 0,62 & 0,05 & 0,04 & 0,04 & 0,08 & 0,01 & 0,04 & 0,45 & 0,09 & 0,27 & 0,18 & 0,02 & 0,1 \\
\hline 11. Química & 2,73 & 0,19 & 1,46 & 3,27 & 2,02 & 2,64 & 2,69 & 0,23 & 1,46 & 3,24 & 0,74 & 1,99 & 1,82 & 0,16 & 0,99 \\
\hline 12. Farmacêutica & 0 & 0,02 & 0,01 & 0,02 & 0,17 & 0,1 & 0 & 0 & 0 & 0,07 & 0,69 & 0,38 & 0,02 & 0,07 & 0,04 \\
\hline 13. Plásticos & 0,04 & 0 & 0,02 & 0,15 & 0,1 & 0,13 & 0 & 0 & 0 & 0,53 & 0,16 & 0,34 & 0,41 & 0,05 & 0,23 \\
\hline 14. Indús & 0,56 & 0,2 & 0,38 & 0,49 & 0,63 & 0,56 & 0,31 & 0,08 & 0,19 & 0,6 & 0,23 & 0,41 & 1,02 & 0,18 & 0,6 \\
\hline 15. Vestuário e Calçados & 0,02 & 0,26 & 0,14 & 0,03 & 0,72 & 0,38 & 0,01 & 0,24 & 0,13 & 0,02 & 0,72 & 0,37 & 0,07 & 1,61 & 0,84 \\
\hline 16. Produtos A & 0,45 & 2,7 & 1,57 & 0,6 & 3,89 & 2,25 & 1,3 & 4,68 & 2,99 & 0,82 & 2,63 & 1,72 & 1,01 & 7,42 & 4,21 \\
\hline 17. Indústrias Diversas & 0,41 & 0,29 & 0,35 & 0,03 & 0,01 & 0,02 & 0,02 & 0,01 & 0,02 & 0,29 & 0,26 & 0,27 & 0,15 & 0,08 & 0,11 \\
\hline 18. SIUP e Comunicações & 3,29 & 0,3 & 1,8 & 2,78 & 0,18 & 1,48 & 1,19 & 0,27 & 0,73 & 1,37 & 0,21 & 0,79 & 1,71 & 0,26 & 0,98 \\
\hline 19. Construção Civil & 0,72 & 2,74 & 1,73 & 0,83 & 3,98 & 2,41 & 0,78 & 4,91 & 2,84 & 0,26 & 1,8 & 1,03 & 0,46 & 2,42 & 1,44 \\
\hline 20. Comércio & 2,88 & 2,48 & 2,68 & 3,44 & 1,61 & 2,52 & 2,56 & 2,06 & 2,31 & 1,83 & 1,75 & 1,79 & 2,33 & 1,63 & 1,98 \\
\hline 21. Transportes & 0,81 & 0,31 & 0,56 & 0,99 & 0,55 & 0,77 & 1,24 & 0,46 & 0,85 & 1,41 & 0,83 & 1,12 & 1,57 & 0,74 & 1,16 \\
\hline 22. Serviços & 3,27 & 4,53 & 3,9 & 1,73 & 5,79 & 3,76 & 5,58 & 5,16 & 5,37 & 2,15 & 5,11 & 3,63 & 1,87 & 3,48 & 2,68 \\
\hline
\end{tabular}


Para o sistema inter-regional, as tabelas 7 e 8 mostram que o índice puro total (PTL) de valor maior do que a média da região indica os setores-chave. Estes foram, praticamente, os mesmos encontrados quando da analisa das tabelas 5 e 6, ou seja, para as regiões de forma isolada. Assim, Agropecuária (1), Produtos Alimentares (16), Construção Civil (19), Comércio (20) e Serviços (22) foram os setores mais dinâmicos em 1985 e 1995, considerando o sistema inter-regional.

Uma constatação importante quando se leva em consideração o sistema interregional é que, de 1985 para 1995, as regiões Nordeste, Norte e Centro-Oeste se integram mais à economia nacional, relativamente às regiões Sudeste e Sul. Em outras palavras, o valor da produção total das três primeiras regiões passou a impactar mais as outras regiões. Isto ocorre porque as regiões Sudeste e Sul reduzem o número de setores-chave, enquanto as outras três o mantém.

Tabela 7

Índices Puros para Frente (PFL), para Trás (PBL) e Total (PTL), sistema inter-regional, Brasil, 1985

\begin{tabular}{|c|c|c|c|c|c|c|c|c|c|}
\hline \multirow{2}{*}{$\begin{array}{l}\text { Regiões e } \\
\text { Setores }\end{array}$} & \multicolumn{3}{|c|}{ Norte } & \multicolumn{3}{|c|}{ Nordeste } & \multicolumn{3}{|c|}{ Centro-Oeste } \\
\hline & PFL & PBL & PTL & PFL & PBL & PTL & PFL & PBL & PTL \\
\hline 1. Agropecuária & 10.423 & 3.268 & 13.690 & 17.643 & 7.297 & 24.940 & 10.324 & 2.422 & 12.745 \\
\hline 2. Mineração & 3.767 & 340 & 4.107 & 12.276 & 126 & 12.402 & 1.090 & 118 & 1.209 \\
\hline 3. Minerais não Metálicos & 856 & 122 & 978 & 2.730 & 144 & 2.874 & 1.564 & 238 & 1.802 \\
\hline 4. Metalurgia & 655 & 179 & 833 & 5.879 & 2.147 & 8.026 & 577 & 227 & 804 \\
\hline 5. Mecânica & 578 & 317 & 896 & 1.774 & 1.113 & 2.887 & 54 & 114 & 168 \\
\hline 6. Material Elétrico & 2.090 & 3.563 & 5.653 & 836 & 929 & 1.765 & 97 & 246 & 343 \\
\hline 7. Material de Transporte & 876 & 409 & 1.286 & 572 & 211 & 783 & 25 & 78 & 103 \\
\hline 8. Madeira e Mobiliário & 1.242 & 1.228 & 2.470 & 683 & 663 & 1.345 & 218 & 355 & 574 \\
\hline 9. Celulose, Papel e Gráfica & 295 & 520 & 815 & 2.167 & 288 & 2.454 & 295 & 95 & 390 \\
\hline 10. Indústria da Borracha & 526 & 25 & 551 & 302 & 89 & 391 & 50 & 5 & 56 \\
\hline 11. Química & 672 & 201 & 872 & 22.019 & 7.001 & 29.020 & 821 & 320 & 1.141 \\
\hline 12. Farmacêutica & 11 & 110 & 121 & 201 & 1.407 & 1.608 & 26 & 85 & 111 \\
\hline 13. Plásticos & 279 & 56 & 335 & 1.353 & 399 & 1.752 & 56 & 16 & 72 \\
\hline 14. Indústria Têxtil & 293 & 316 & 608 & 5.666 & 2.761 & 8.427 & 288 & 246 & 533 \\
\hline 15. Vestuário e Calçados & 14 & 215 & 228 & 280 & 4.334 & 4.614 & 28 & 462 & 490 \\
\hline 16. Produtos Alimentares & 764 & 3.451 & 4.215 & 3.487 & 24.608 & 28.095 & 1.220 & 4.523 & 5.743 \\
\hline 17. Indústrias Diversas & 404 & 230 & 634 & 1.495 & 36 & 1.531 & 10 & 10 & 20 \\
\hline 18. SIUP e Comunicações & 1.204 & 510 & 1.713 & 5.460 & 803 & 6.263 & 2.180 & 407 & 2.587 \\
\hline 19. Construção Civil & 662 & 19.867 & 20.529 & 2.018 & 22.308 & 24.326 & 430 & 4.610 & 5.040 \\
\hline 20. Comércio & 3.384 & 2.181 & 5.565 & 12.725 & 3.789 & 16.514 & 3.872 & 3.142 & 7.014 \\
\hline 21. Transportes & 2.711 & 2.182 & 4.893 & 3.491 & 4.173 & 7.664 & 2.060 & 1.535 & 3.595 \\
\hline 22. Serviços & 2.789 & 5.755 & 8.545 & 7.014 & 27.050 & 34.064 & 6.418 & 6.215 & 12.633 \\
\hline Média & 1.568 & 2.048 & 3.615 & 5.003 & 5.076 & 10.079 & 1.441 & 1.158 & 2.599 \\
\hline
\end{tabular}




\section{Tabela 7}

Índices Puros para Frente (PFL), para Trás (PBL) e Total (PTL), sistema inter-regional, Brasil, 1985 (em bilhões de Cruzeiros) - continuação

\begin{tabular}{l|rrr|rrr}
\hline Regiões e & \multicolumn{3}{|c|}{ Sudeste } & \multicolumn{3}{c}{ Sul } \\
Setores & \multicolumn{1}{|c}{ PFL } & PBL & \multicolumn{1}{c}{ PTL } & PFL & PBL & \multicolumn{1}{c}{ PTL } \\
\hline 1. Agropecuária & $\mathbf{4 3 . 9 1 0}$ & 17.431 & $\mathbf{6 1 . 3 4 1}$ & $\mathbf{3 9 . 5 7 6}$ & $\mathbf{9 . 2 8 1}$ & $\mathbf{4 8 . 8 5 7}$ \\
2. Mineração & 22.263 & 4.205 & 26.467 & 2.423 & 399 & 2.822 \\
3. Minerais não Metálicos & 23.037 & 2.224 & 25.261 & 5.058 & 765 & 5.824 \\
4. Metalurgia & $\mathbf{9 7 . 3 3 3}$ & 16.454 & $\mathbf{1 1 3 . 7 8 8}$ & 7.617 & 2.730 & 10.347 \\
5. Mecânica & 25.568 & 22.116 & 47.684 & 4.780 & 6.324 & 11.104 \\
6. Material Elétrico & 14.502 & 27.102 & 41.604 & 1.505 & 4.304 & 5.809 \\
7. Material de Transporte & 24.754 & $\mathbf{4 2 . 8 0 7}$ & $\mathbf{6 7 . 5 6 1}$ & 1.268 & 4.332 & 5.600 \\
8. Madeira e Mobiliário & 5.141 & 8.236 & 13.377 & 4.428 & 6.518 & 10.946 \\
9. Celulose, Papel e Gráfica & 26.653 & 6.194 & 32.846 & 6.634 & 1.712 & 8.346 \\
10. Indústria da Borracha & 13.608 & 1.111 & 14.720 & 1.580 & 243 & 1.823 \\
11. Química & $\mathbf{1 0 1 . 0 6 3}$ & 26.680 & $\mathbf{1 2 7 . 7 4 3}$ & $\mathbf{2 0 . 3 8 9}$ & 6.028 & $\mathbf{2 6 . 4 1 7}$ \\
12. Farmacêutica & 4.275 & 15.433 & 19.707 & 197 & 776 & 973 \\
13. Plásticos & 12.972 & 2.502 & 15.474 & 2.848 & 623 & 3.471 \\
14. Indústria Têxtil & 26.871 & 9.650 & 36.521 & 7.712 & 2.630 & 10.342 \\
15. Vestuário e Calçados & 1.352 & $\mathbf{3 6 . 2 3 0}$ & 37.583 & 1.405 & $\mathbf{1 9 . 3 5 6}$ & $\mathbf{2 0 . 7 6 1}$ \\
16. Produtos Alimentares & 16.220 & $\mathbf{8 4 . 7 2 1}$ & $\mathbf{1 0 0 . 9 4 1}$ & $\mathbf{1 7 . 0 7 8}$ & $\mathbf{6 7 . 4 6 5}$ & $\mathbf{8 4 . 5 4 2}$ \\
17. Indústrias Diversas & 9.029 & 4.531 & 13.559 & 1.043 & 752 & 1.795 \\
18. SIUP e Comunicações & 24.575 & 5.517 & 30.092 & $\mathbf{8 . 9 1 6}$ & 2.074 & 10.989 \\
19. Construção Civil & 8.167 & $\mathbf{9 1 . 5 3 8}$ & $\mathbf{9 9 . 7 0 5}$ & 1.693 & $\mathbf{1 8 . 9 6 8}$ & $\mathbf{2 0 . 6 6 1}$ \\
20. Comércio & $\mathbf{4 6 . 5 1 2}$ & $\mathbf{3 6 . 6 7 4}$ & $\mathbf{8 3 . 1 8 6}$ & $\mathbf{1 7 . 6 5 2}$ & $\mathbf{1 3 . 3 9 5}$ & $\mathbf{3 1 . 0 4 7}$ \\
21. Transportes & $\mathbf{2 9 . 8 6 1}$ & 24.264 & 54.125 & $\mathbf{1 2 . 1 2 3}$ & 8.811 & $\mathbf{2 0 . 9 3 4}$ \\
22. Serviços & $\mathbf{5 1 . 6 7 7}$ & $\mathbf{1 1 4 . 1 4 0}$ & $\mathbf{1 6 5 . 8 1 7}$ & $\mathbf{9 . 9 2 2}$ & $\mathbf{2 6 . 6 0 5}$ & $\mathbf{3 6 . 5 2 7}$ \\
\hline Média & 28.607 & 27.262 & 55.868 & 7.993 & 9.277 & 17.270 \\
\hline Fonte: Cálculos dos autores. & \multicolumn{7}{|c}{} & \\
& \multicolumn{7}{|c|}{} & & &
\end{tabular}


Tabela 8

Índices Puros para Frente (PFL), para Trás (PBL) e Total (PTL), sistema inter-regional, Brasil, 1995

\begin{tabular}{|c|c|c|c|c|c|c|c|c|c|}
\hline Regiões e & & Norte & & & Nordeste & & & Centro-Oest & \\
\hline Setores & PFL & PBL & PTL & PFL & PBL & PTL & PFL & PBL & PTL \\
\hline 1. Agropecuária & 2.333 .374 & 596.187 & 2.929 .561 & 4.758 .328 & 1.855 .217 & 6.613.546 & 8.228 .152 & 1.407 .964 & 9.636.116 \\
\hline 2. Mineração & 1.185 .065 & 26.413 & 1.211 .478 & 1.701 .536 & 2.934 & 1.704 .469 & 551.815 & 29.573 & 581.388 \\
\hline 3. Minerais não Metálicos & 243.696 & 37.150 & 280.846 & 1.149 .321 & 105.768 & 1.255 .088 & 553.483 & 88.879 & 642.362 \\
\hline 4. Metalurgia & 242.754 & 76.477 & 319.231 & 1.547 .100 & 606.776 & 2.153 .876 & 252.459 & 100.637 & 353.096 \\
\hline 5. Mecânica & 321.853 & 109.154 & 431.008 & 640.494 & 95.303 & 735.797 & 26.051 & 38.865 & 64.917 \\
\hline 6. Material Elétrico & 757.419 & 1.610 .032 & 2.367 .451 & 367.313 & 581.388 & 948.701 & 46.636 & 146.410 & 193.046 \\
\hline 7. Material de Transporte & 226.619 & 194.584 & 421.204 & 165.818 & 104.923 & 270.741 & 9.648 & 34.385 & 44.033 \\
\hline 8. Mad & 210 & 439.346 & 75 & 3( & 272.725 & 42 & 51 & 23 & 660 \\
\hline 9. Celul & 206.130 & 531.970 & 738.100 & 548.765 & 64.944 & 613.709 & 406.952 & 136.387 & 543.339 \\
\hline ia da Borracha & 318.803 & 188.798 & 507.601 & 81.572 & 38.808 & .380 & 58.400 & 10.827 & 69.227 \\
\hline 11. Quí & 921.260 & 192.084 & 1.11 & 8.672 & 1.542 .390 & 10.21 & 1.961 .667 & 374.689 & 2.336.357 \\
\hline 12. Farn & 835 & 10.995 & 11.829 & 32.545 & 299.014 & 559 & 651 & 3.886 & 4.536 \\
\hline 13. Plásticos & 615 & 2.416 & .031 & 257.438 & 74.772 & .210 & .709 & 817 & 3.526 \\
\hline 14. Inc & 193 & 152.005 & & 1.38 & 474.299 & & 229.898 & 153.064 & 382.962 \\
\hline 15. Vest & 6.417 & 116.442 & 122.859 & 57.522 & 1.611 .525 & 547 & 13.135 & 344.448 & 357.583 \\
\hline 16. Produ & 278.131 & 1.267 .045 & 1.545 .176 & 1.122 .108 & 5.928 .125 & 7.050 .233 & 1.237 .202 & 3.770 .106 & 5.007 .308 \\
\hline 17. Indú & & 131.838 & & & 10.402 & & 17.006 & 5.852 & 22.858 \\
\hline 18. SIUP & 1.108 .705 & 243.710 & 1.352 .414 & 3.301 .836 & 297.638 & 3.599 .475 & 1.018 .688 & 185.727 & 1.204 .416 \\
\hline 19. Construção Civil & 241.659 & 4.464 .052 & 4.705 .711 & 984.763 & 7.745 .644 & 8.730 .407 & 545.408 & 6.928 .203 & 7.473.611 \\
\hline 20. Com & 1.327 .319 & 1.108 .166 & 2.435 & 6.13 & 2.451 .004 & 8.5 & 1.902 .227 & 1.719 .156 & 3.621 .383 \\
\hline 21. Trans & 376.216 & 224.987 & 601.203 & 1.378 .060 & 1.037 .732 & 91 & 922.935 & 510.021 & 1.432 .956 \\
\hline 22. Serviços & 1.118 .064 & 2.676 .645 & 3.794 .709 & 2.669.098 & 10.526.975 & 13.196.073 & 5.018.525 & 5.683 .213 & 10.701 .739 \\
\hline Média & 545.624 & 654.568 & 1.200 .192 & 1.695 .614 & 1.624 .014 & \begin{tabular}{|l|}
3.319 .628 \\
\end{tabular} & 1.053 .018 & 995.955 & 2.048 .974 \\
\hline
\end{tabular}

Fonte: Cálculos dos autores. 
Tabela 8

Índices Puros para Frente (PFL), para Trás (PBL) e Total (PTL), sistema inter-regional, Brasil, 1995 (em mil Reais) - continuação

\begin{tabular}{|c|c|c|c|c|c|c|}
\hline \multirow{2}{*}{$\begin{array}{l}\text { Regiões e } \\
\text { Setores }\end{array}$} & \multicolumn{3}{|c|}{ Sudeste } & \multicolumn{3}{|c|}{ Sul } \\
\hline & PFL & PBL & PTL & PFL & PBL & PTL \\
\hline 1. Agropecuária & 16.585 .963 & 6.122 .373 & 22.708 .337 & 17.826 .857 & 2.921 .512 & 20.748 .368 \\
\hline 2. Mineração & 3.697 .475 & 2.173 .570 & 5.871 .044 & 344.204 & 192.710 & 536.914 \\
\hline 3. Minerais não Metálicos & 8.850 .135 & 649.081 & 9.499 .216 & 1.974 .639 & 271.865 & 2.246 .504 \\
\hline 4. Metalurgia & 30.691 .785 & 5.092 .095 & 35.783 .880 & 2.267 .312 & 771.721 & 3.039 .033 \\
\hline 5. Mecânica & 6.902 .533 & 5.345 .374 & 12.247 .907 & 2.292 .542 & 2.384 .617 & 4.677 .159 \\
\hline 6. Material Elétrico & 4.066 .548 & 10.591 .720 & 14.658 .269 & 623.879 & 2.216 .218 & 2.840 .097 \\
\hline 7. Material de Transporte & 6.062 .209 & 20.156 .890 & 26.219 .099 & 407.008 & 1.603 .957 & 2.010 .965 \\
\hline 8. Madeira e Mobiliário & 1.581 .733 & 2.416 .971 & 3.998 .704 & 1.814 .077 & 2.458 .623 & 4.272 .700 \\
\hline 9. Celulose, Papel e Gráfica & 9.517 .652 & 2.548 .253 & 12.065 .905 & 2.373 .503 & 679.000 & 3.052 .504 \\
\hline 10. Indústria da Borracha & 4.506 .965 & 371.245 & 4.878 .210 & 455.100 & 117.475 & 572.575 \\
\hline 11. Química & 33.635 .827 & 3.921 .819 & 37.557 .646 & 4.634 .832 & 685.937 & 5.320 .769 \\
\hline 12. Farmacêutica & 899.999 & 6.566 .318 & 7.466 .317 & 43.818 & 272.102 & 315.919 \\
\hline 13. Plásticos & 5.149 .780 & 825.467 & 5.975 .247 & 1.035 .565 & 200.051 & 1.235 .615 \\
\hline 14. Indústria Têxtil & 5.898 .969 & 1.960 .167 & 7.859 .136 & 2.540 .442 & 768.994 & 3.309 .436 \\
\hline 15. Vestuário e Calçados & 221.800 & 6.841 .950 & 7.063 .750 & 294.000 & 5.406 .004 & 5.700 .004 \\
\hline 16. Produtos Alimentares & 7.729 .417 & 35.867 .787 & 43.597 .203 & 6.668 .443 & 19.926 .716 & 26.595.160 \\
\hline 17. Indústrias Diversas & 2.745 .439 & 2.061 .726 & 4.807 .165 & 371.743 & 356.254 & 727.998 \\
\hline 18. SIUP e Comunicações & 11.175 .337 & 1.905 .330 & 13.080 .667 & 5.066 .239 & 845.175 & 5.911 .414 \\
\hline 19. Construção Civil & 2.367 .785 & 15.982 .862 & 18.350 .648 & 1.074 .116 & 10.926 .874 & 12.000 .991 \\
\hline 20. Comércio & 15.052 .577 & 14.897 .114 & 29.949 .692 & 6.111 .005 & 5.888 .950 & 11.999 .955 \\
\hline 21. Transportes & 11.343 .479 & 7.427 .664 & 18.771 .143 & 4.222 .053 & 2.564 .564 & 6.786 .617 \\
\hline 22. Serviços & 21.342 .687 & 49.857 .599 & 71.200 .286 & 4.510 .664 & 13.566.500 & 18.077 .164 \\
\hline Média & 9.546 .641 & 9.253 .790 & 18.800 .431 & 3.043 .275 & 3.410 .265 & 6.453 .539 \\
\hline
\end{tabular}

Outra informação revelada pelas tabelas 7 e 8 é que o total de setores-chave em 1995 é menor do que em 1985, o que indica que a economia nacional está recebendo e ofertando produtos de setores externos ao sistema, vale dizer, do exterior.

\subsection{Comparação e consolidação dos índices de Rasmussen/Hirs- chman e puros}

A comparação dos índices de Rasmussen/Hirschman e puro total para o sistema inter-regional mostra classificação diferente para os setores-chave, com o segundo apresentando número maior de setores dinâmicos (quadro 1). Isto ocorre em razão de que nos índices de Hirschman/Rasmussen o mais importante para a definição de setores-chave é a estrutura interna da economia, independente do valor da produção total. Por outro lado, os índices puros consideram não apenas a estrutura interna mas, também, o nível de produção em cada setor da economia. 
Quadro I - Setores-chave consolidados - índices de ligações de Rasmussen/Hirschman (R-H) e puro total (PTL), sistema inter-regional, Brasil, 1985 e 1995

\begin{tabular}{|c|c|c|c|c|c|c|c|c|c|c|c|}
\hline \multirow{3}{*}{$\begin{array}{l}\text { Regiões } \\
\mathrm{e}\end{array}$} & \multicolumn{2}{|c|}{ Norte } & \multicolumn{2}{|c|}{ Nordeste } & \multicolumn{2}{|c|}{ Centro-Oeste } & \multicolumn{2}{|c|}{ Sudeste } & \multicolumn{3}{|c|}{ Sul } \\
\hline & \multirow{2}{*}{$\frac{\mathrm{R}-\mathrm{H}}{19851995}$} & PTL & $\mathrm{R}-\mathrm{H}$ & PTL & \multirow{2}{*}{\begin{tabular}{|c|}
$\mathrm{R}-\mathrm{H}$ \\
$1985 \quad 1995$ \\
\end{tabular}} & PTL & $\mathrm{R}-\mathrm{H}$ & PTL & $\mathrm{R}-\mathrm{H}$ & \multicolumn{2}{|c|}{ PTL } \\
\hline & & \begin{tabular}{|ll|l}
1985 & 1995 \\
\end{tabular} & $1985 \quad 1995$ & 19851995 & & 19851995 & 19851995 & \begin{tabular}{|ll|l}
1985 & 1995 & 1
\end{tabular} & \begin{tabular}{|ll|l|}
1985 & 1995 \\
\end{tabular} & 1985 & 1995 \\
\hline 1. Agropecuária & & $\oplus$ & & $\oplus$ & & $\oplus$ & & $\oplus$ & & $\oplus$ & $\oplus$ \\
\hline 2. Mineração & & $\oplus$ & & $\oplus$ & & & $\oplus$ & & & & \\
\hline 3. Minerais não Metálicos & & & & & & & $\oplus$ & & & & \\
\hline 4. Metalurgia & & & $\oplus$ & & & & $\oplus$ & $\oplus$ & $\oplus$ & & \\
\hline 5. Mecânica & & & & & & & $\oplus$ & & $\oplus$ & & \\
\hline 6. Material Elétrico & & $\oplus$ & & & & & $\oplus$ & & & & \\
\hline 7. Material de Transporte & & & & & & & $\oplus$ & $\oplus$ & & & \\
\hline 8. Madeira e Mobiliário & & & & & & & & & & & \\
\hline 9. Celulose, Papel e Gráfica & & & & & & & $\oplus$ & & & & \\
\hline 10. Indústria da Borracha & & & & & & & $\oplus$ & & & & \\
\hline 11. Química & & & $\oplus$ & $\oplus$ & & $\oplus$ & $\oplus$ & $\oplus$ & & $\oplus$ & \\
\hline 12. Farmacêutica & & & & & & & & & & & \\
\hline 13. Plásticos & & & & & & & $\oplus$ & & & & \\
\hline 14. Indústria Têxtil & & & $\oplus$ & & & & $\oplus$ & & $\oplus$ & & \\
\hline 15. Vestuário e Calçados & & & & & & & & & & $\oplus$ & \\
\hline 16. Produtos Alimentares & & $\oplus$ & & $\oplus$ & & $\oplus$ & $\oplus$ & $\oplus$ & $\oplus$ & $\oplus$ & $\oplus$ \\
\hline 17. Indústrias Diversas & & & & & & & & & & & \\
\hline 18. SIUP e Comunicações & & $\oplus$ & & $\oplus$ & & & & & & & \\
\hline 19. Construção Civil & & $\oplus$ & & $\oplus$ & & $\oplus$ & & $\oplus$ & & $\oplus$ & $\oplus$ \\
\hline 20. Comércio & & $\oplus$ & & $\oplus$ & & $\oplus$ & & $\oplus$ & & $\oplus$ & $\oplus$ \\
\hline 21. Transportes & & $\oplus$ & & & & $\oplus$ & & & & $\oplus$ & $\oplus$ \\
\hline 22. Serviços & & $\oplus$ & & $\oplus$ & & $\oplus$ & & $\oplus$ & & $\oplus$ & $\oplus$ \\
\hline
\end{tabular}

Fonte: Tabelas 3, 4, 7 e 8 . 
O quadro 1 apresenta a consolidação dos setores-chave encontrados pelos índices de Rasmussen/Hirschman, via critério restrito, e pelos índices puros totais, acima da média, para o sistema inter-regional. Três regiões se destacaram por apresentar setores-chave em ambos os conceitos para os dois anos estudados: a Sudeste com os setores Metalurgia (4) e Material de Transporte (7), a Nordeste com Química (11) e a Sul com o setor Produtos Alimentares (16).

\subsection{Interação entre as regiões brasileiras}

O comportamento das regiões em termos de suas ligações com as outras regiões do sistema, permitindo examinar a intensidade das relações entre elas e evidenciar as mudanças ocorridas no tempo, é mostrado nas tabelas 9 e 10.

A região Sudeste é a mais importante receptora do impacto do valor da produção total do sistema, apresentando, tanto para 1985 quanto para 1995, o maior PFL, isto é, 48,98\% e 46,65\%, respectivamente. O valor da produção total da região Sudeste é, também, o grande responsável por impactar o resto da economia, uma vez que detém os maiores valores do PBL para os anos analisados, 36,41 e 39,25 para 1985 e 1995, respectivamente (tabela 9).

É interessante frisar a manutenção do rank das regiões Sudeste, Sul e Nordeste no período, apesar da tendência de redução no valor dos índices, e o crescimento de todos os índices puros da região Centro-Oeste, elevando sua posição no rank, contrariamente à Norte (tabela 9).

Tabela 9

Índices de ligações para Trás (PBL), para Frente (PFL) e Total (PTL), sistema inter-regional, Brasil, 1985 e 1995 (em \%)

\begin{tabular}{|c|c|c|c|c|c|c|c|c|c|c|c|c|}
\hline \multirow[t]{2}{*}{ Regiões } & \multicolumn{4}{|c|}{ PBL } & \multicolumn{4}{|c|}{ PFL } & \multicolumn{4}{|c|}{ PTL } \\
\hline & 1985 & Rank & 1995 & Rank & 1985 & Rank & 1995 & Rank & 1985 & Rank & 1995 & Rank \\
\hline Norte & 11,14 & 4 & 8,07 & 5 & 7,26 & 4 & 5,68 & 5 & 9,2 & 4 & 6,88 & 5 \\
\hline Nordeste & 16,17 & 3 & 12,61 & 3 & 15,64 & 3 & 14,29 & 3 & 15,91 & 3 & 13,45 & 3 \\
\hline Centro-Oeste & 4,87 & 5 & 9,94 & 4 & 7,2 & 5 & 11,28 & 4 & 6,04 & 5 & 10,61 & 4 \\
\hline Sudeste & 36,41 & 1 & 39,25 & 1 & 48,98 & 1 & 46,65 & 1 & 42,69 & 1 & 42,95 & 1 \\
\hline Sul & 31,42 & 2 & 30,14 & 2 & 20,9 & 2 & 22,11 & 2 & 26,16 & 2 & 26,12 & 2 \\
\hline Total & 100 & & 100 & & 100 & & 100 & & 100 & & 100 & \\
\hline
\end{tabular}

Fonte: Cálculos dos autores. 
A tabela 10 mostra como o total da produção de dada região é afetado pela sua própria produção e pela produção das demais regiões do sistema. Nas linhas está a produção de cada região e nas colunas a região da qual originou a demanda que induziu esta produção. Como exemplo, tomando-se o caso da região Norte em 1985, verificou-se que, do valor da produção de todos os seus setores, $82,34 \%$ foram devidos à produção necessária para suprir a demanda final própria (incluindo exportações) e o restante $(17,66 \%)$ foram gerados pelas necessidades de produção das outras regiões do sistema.

Tabela 10

Produção das regiões brasileiras induzida pelas demandas finais, 1985 e 1995 (em \%)

\begin{tabular}{l|cc|cc|cc|cc|cc|cc}
\hline Regiões & \multicolumn{2}{|c|}{ Norte } & \multicolumn{2}{c|}{ Nordeste } & \multicolumn{2}{c|}{ Centro-Oeste } & \multicolumn{2}{c|}{ Sudeste } & \multicolumn{2}{c}{ Sul } & \multicolumn{2}{c}{ Total } \\
& 1985 & 1995 & 1985 & 1995 & 1985 & 1995 & 1985 & 1995 & 1985 & 1995 & 1985 & 1995 \\
\hline Norte & 82,34 & 87,96 & 0,81 & 0,42 & 0,43 & 0,78 & 12,19 & 7,74 & 4,24 & 3,1 & 100 & 100 \\
Nordeste & 0,7 & 0,49 & 88,19 & 89,53 & 0,24 & 0,64 & 8,54 & 6,91 & 2,32 & 2,44 & 100 & 100 \\
Centro-Oeste & 0,89 & 0,22 & 1,5 & 0,57 & 73,62 & 86,6 & 20,64 & 10,65 & 3,35 & 1,96 & 100 & 100 \\
Sudeste & 1,33 & 0,97 & 2,13 & 1,51 & 0,51 & 1,15 & 92,4 & 92,66 & 3,63 & 3,71 & 100 & 100 \\
Sul & 0,89 & 0,49 & 2,16 & 1,15 & 0,37 & 0,67 & 10,66 & 8,56 & 85,92 & 89,13 & 100 & 100 \\
\hline Total & 4,41 & 4,46 & 13,58 & 12,18 & 2,56 & 7,45 & 62,91 & 56,86 & 16,53 & 19,06 & 100 & 100 \\
\hline \multicolumn{1}{l}{ Fonte: Cálculos dos autores. }
\end{tabular}

A comparação entre os anos de 1985 e 1995 revela uma redução no intercâmbio entre as regiões brasileiras, significando menor dependência entre essas regiões na geração de demanda para seus produtos e serviços. Isto pode ser visto pelo aumento da parcela do valor da produção da economia das regiões devida à produção necessária para suprir a demanda final própria e a conseqüente redução da parcela do valor da produção das economias das regiões necessária para a produção das outras regiões do sistema. Por outro lado, o processo de abertura instaurado no Brasil, notadamente a partir do início dos anos 90, incrementou a internacionalização do processo produtivo, estreitando as ligações das regiões brasileiras com o exterior e elevando, conseqüentemente, o grau de dependência das economias regionais relativamente a este. Esta constatação confirma os resultados apontados quando da análise dos índices de ligação.

\section{Desagregação da Interação Regional}

A demanda final das regiões desencadeia efeitos diretos e indiretos, induzindo produção diferenciada dependendo da estrutura econômica intersetorial e interregional.

Pela tabela 10 pode-se observar a produção das regiões brasileiras desagregada pela origem das demandas finais para os anos de 1985 e 1995. Como exemplo, 
a primeira linha mostra que a região Norte apresentou $82,34 \%$ de sua produção induzidos por sua própria demanda final, 0,81\% pela demanda final do Nordeste, 0,43\% pela do Centro-Oeste e assim por diante, considerando o ano de 1985. Desse modo, a demanda induzida pelas outras regiões correspondeu a $17,66 \%$ do valor da produção da região Norte.

Nos dois anos analisados, a região Sudeste se manteve com a maior participação nas demandas finais das outras regiões. Percebe-se, no entanto, queda nesta participação para essa região e para as demais, exceto para a Centro-Oeste. Contrariamente, houve uma elevação da parcela induzida pelas demandas finais das próprias regiões, com destaque para a Centro-Oeste (tabela 10).

Estes resultados mostram que, exceto para a região Centro-Oeste, as demandas finais das regiões perderam importância no período enquanto indutoras da produção das demais regiões, ou seja, as regiões ficaram menos interdependentes em 1995, relativamente a 1985. Desse modo, a maior integração detectada pela análise dos índices de ligação ocorreu entre as regiões brasileiras e o exterior, fruto da abertura da economia nos anos 90 .

\section{Desagregação Setorial: Impactos da Demanda Final Própria}

A produção induzida pela demanda final de cada região pode, também, ser desagregada por setor. Desse modo, utilizando-se do exemplo anterior, detectou-se qual a participação da Agropecuária, da Mineração, etc., nos 82,34\% da produção do Norte induzidos pela sua própria demanda final, nos $0,81 \%$ induzidos pela demanda final do Nordeste, nos $0,43 \%$ pela do Centro-Oeste e, assim, sucessivamente, conforme as regiões indutoras.

Estas participações setoriais estão organizadas nas figuras 3 e 4, construídas incluindo os setores que apresentaram participações iguais ou maiores do que $5 \%$ por convenção. Portanto, as porcentagens somadas não totalizam 100\% por região. 
Figura 3

Produção das grandes regiões e setores induzida pela demanda final própria, Brasil, 1985.

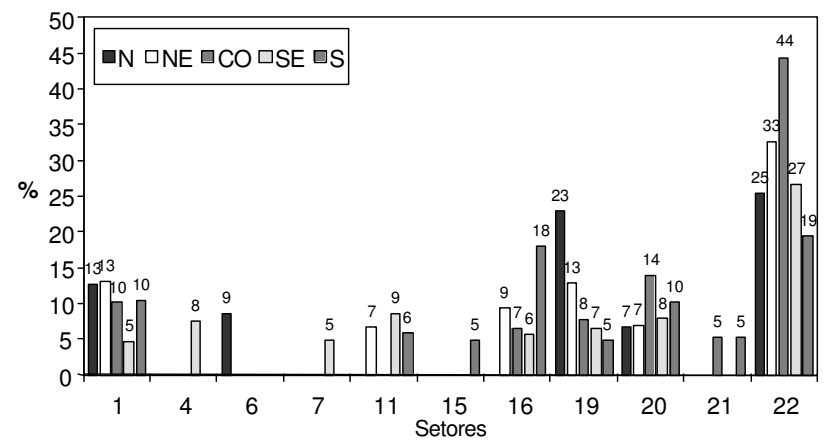

Fonte: Cálculo dos autores.

As figuras 3 e 4 apresentam a distribuição da produção setorial das regiões considerando suas próprias demandas finais, o que permite identificar a característica da estrutura produtiva de cada uma delas.

O impacto da demanda final de cada região sobre seus setores produtivos em 1985 está ilustrado na figura 3. Tomando a primeira barra desta figura, tem-se que a produção do setor Agropecuária (1) da região Norte representa $13 \%$ do total da produção induzida pela demanda final desta região, o setor Material Elétrico (6) $9 \%$, o setor Construção Civil (19) 23\%, e assim por diante.

Figura 4

Produção das grandes regiões e setores induzida pela demanda final própria, Brasil, 1995

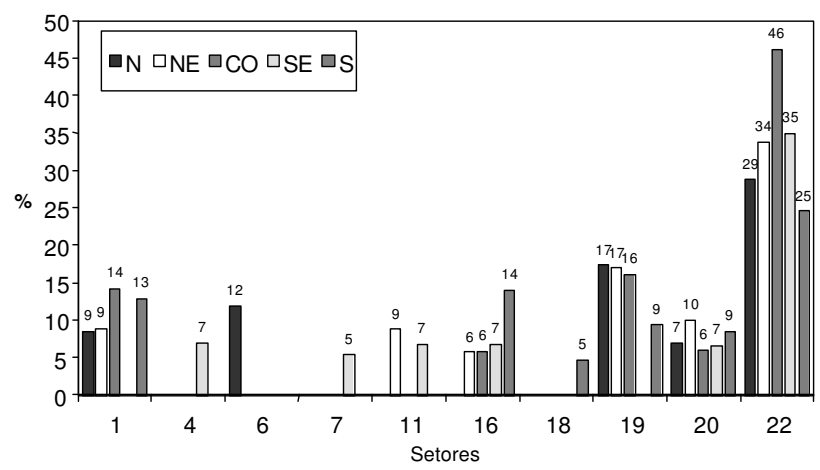

Fonte: Cálculo dos autores. 
A observação geral das figuras 3 e 4 permite apontar os setores Agropecuária (1), Produtos Alimentares (16), Construção Civil (19), Comércio (20) e Serviços (22) como os que apresentaram a maior parcela de produção induzida pelas demandas finais próprias considerando todas as regiões em 1985 e 1995, respectivamente. É interessante notar que o setor Serviços (22) foi o único que elevou sua participação na produção induzida própria de todas as regiões de 1985 para 1995.

Considerando as regiões separadamente, verifica-se que na região Norte os setores Construção Civil (19) e Serviços (22) são os mais impactados pela própria demanda final tanto em 1985 quanto em 1995.

Para a região Nordeste cabe salientar os setores Agropecuária (1), Química (11), Produtos Alimentares (16), Construção Civil (19), Comércio (20) e Serviços (22) como os de maior participação na produção induzida pela própria demanda final nos anos estudados.

Na região Centro-Oeste os destaques ficaram com os setores Construção Civil (19), Comércio (20) e Serviços (22) em 1985, Construção Civil (19) e Serviços (22) em 1995 e Agropecuária (1) em ambos os anos.

No total da produção da região Sudeste induzido pela sua demanda final os setores mais participativos foram Metalurgia (4), Química (11), Produtos Alimentares (16), Comércio (20) e Serviços (22) para ambos os anos.

Por fim, a região Sul tem nos setores Agropecuária (1), Produtos Alimentares (16), Construção Civil (19), Comércio (20) e Serviços (22) os maiores participantes na produção induzida pela sua demanda final para 1985 e 1995.

Assim, quatro tendências são notadas entre 1985-95 no que se refere aos impactos da demanda final própria: a) a redução do número de regiões cuja produção própria aciona os diversos setores de sua economia; b) a redução do número de setores impactados pela demanda própria das regiões, embora as estruturas produtivas tenham, praticamente, mantido as características; c) a redução da participação dos setores comuns aos dois anos analisados na produção induzida pelas demandas finais de cada região, exceto do setor Serviços (22); e d) a elevação da proporção do setor Serviços (22) na produção total das regiões. Estas constatações indicam, por um lado, maior desenvolvimento da economia nacional com o crescimento do setor Serviços (22) e, por outro, redução da participação dos setores-chave na produção induzida pelas regiões, o que revela a elevação da importância para a produção local de setores externo à economia nacional. 


\section{Desagregação Setorial: Impactos da Demanda Final de Outras Regiões}

As tabelas 11 e 12 mostram, para 1985 e 1995, respectivamente, os impactos na produção de cada região, por setor, induzidos pelas outras regiões. Novamente, tomando a região Norte como exemplo, identifica-se na tabela 11 como a parcela de sua produção induzida pela outras regiões se distribuiu entre os setores de sua economia em 1985. A primeira coluna indica, respectivamente, que $40 \%$ da demanda final da região Nordeste sobre a Norte foi exercida no setor Agropecuária (1), 17\% na Mineração (2), $6 \%$ na Mecânica (5), e assim por diante.

Tabela 11

Produção setorial regional induzida pela demanda final de outras regiões, grandes regiões, Brasil, 1985 (em \%)

\begin{tabular}{|c|c|c|c|c|c|c|c|c|c|c|c|c|c|c|c|c|c|c|c|c|}
\hline \multirow[t]{2}{*}{ Setores } & \multicolumn{4}{|c|}{ Norte } & \multicolumn{4}{|c|}{ Nordeste } & \multicolumn{4}{|c|}{ Centro-Oeste } & \multicolumn{4}{|c|}{ Sudeste } & \multicolumn{4}{|c|}{ Sul } \\
\hline & $\mathrm{NE}$ & $\mathrm{CO}$ & $\mathrm{SE}$ & $\mathrm{S}$ & $\mathrm{N}$ & $\mathrm{CO}$ & $\mathrm{SE}$ & $\mathrm{S}$ & $\mathrm{N}$ & $\mathrm{NE}$ & $\mathrm{SE}$ & $\mathrm{S}$ & $\mathrm{N}$ & $\mathrm{NE}$ & $\mathrm{CO}$ & $\mathrm{S}$ & $\mathrm{N}$ & $\mathrm{NE}$ & $\mathrm{CO}$ & $\mathrm{SE}$ \\
\hline 1 & 40 & 43 & 33 & 56 & 3 & 10 & 7 & 12 & 7 & 33 & 53 & 10 & 2 & 6 & 4 & 5 & 5 & 19 & 15 & 33 \\
\hline 2 & 17 & 15 & 18 & 11 & 11 & 15 & 17 & 15 & 9 & 5 & 4 & 10 & 3 & 3 & 4 & 5 & 2 & 1 & 2 & 1 \\
\hline 3 & 1 & 1 & 1 & 1 & 3 & 0 & 0 & 0 & 29 & 11 & 2 & 7 & 14 & 6 & 1 & 2 & 19 & 5 & 1 & 1 \\
\hline 4 & 1 & 0 & 1 & 0 & 21 & 5 & 7 & 5 & 3 & 1 & 0 & 6 & 18 & 13 & 17 & 22 & 7 & 4 & 9 & 1 \\
\hline 5 & 6 & 1 & 1 & 1 & 3 & 1 & 1 & 1 & 0 & 0 & 0 & 0 & 4 & 4 & 5 & 4 & 3 & 3 & 5 & 1 \\
\hline 6 & 6 & 7 & 12 & 5 & 7 & 0 & 0 & 0 & 2 & 0 & 0 & 0 & 8 & 2 & 3 & 3 & 5 & 1 & 2 & 0 \\
\hline 7 & 2 & 3 & 5 & 2 & 4 & 0 & 1 & 0 & 0 & 0 & 0 & 0 & 5 & 5 & 6 & 3 & 1 & 1 & 2 & 0 \\
\hline 8 & 1 & 4 & 4 & 3 & 1 & 0 & 0 & 0 & 0 & 0 & 1 & 0 & 0 & 0 & 1 & 0 & 2 & 1 & 4 & 6 \\
\hline 9 & 1 & 1 & 1 & 1 & 2 & 0 & 0 & 0 & 1 & 1 & 0 & 1 & 2 & 4 & 7 & 3 & 2 & 3 & 7 & 1 \\
\hline 10 & 4 & 2 & 2 & 1 & 1 & 0 & 0 & 0 & 0 & 0 & 0 & 0 & 1 & 3 & 3 & 3 & 1 & 1 & 2 & 0 \\
\hline 11 & 1 & 1 & 1 & 1 & 23 & 30 & 32 & 30 & 3 & 4 & 1 & 3 & 17 & 23 & 26 & 19 & 15 & 16 & 19 & 6 \\
\hline 12 & 0 & 0 & 0 & 0 & 1 & 0 & 0 & 0 & 0 & 0 & 0 & 0 & 1 & 2 & 1 & 1 & 0 & 0 & 0 & 0 \\
\hline 13 & 0 & 0 & 0 & 0 & 3 & 1 & 1 & 1 & 0 & 0 & 0 & 0 & 2 & 2 & 3 & 1 & 3 & 2 & 2 & 1 \\
\hline 14 & 1 & 0 & 0 & 0 & 2 & 6 & 8 & 9 & 0 & 2 & 0 & 2 & 1 & 7 & 4 & 3 & 1 & 6 & 3 & 1 \\
\hline 15 & 0 & 0 & 0 & 0 & 0 & 0 & 0 & 0 & 0 & 0 & 0 & 0 & 0 & 0 & 0 & 0 & 1 & 1 & 1 & 1 \\
\hline 16 & 3 & 2 & 2 & 2 & 2 & 4 & 3 & 5 & 2 & 8 & 4 & 2 & 1 & 4 & 3 & 3 & 7 & 19 & 9 & 24 \\
\hline 17 & 3 & 1 & 1 & 1 & 1 & 1 & 1 & 1 & 0 & 0 & 0 & 0 & 1 & 1 & 2 & 1 & 0 & 1 & 1 & 0 \\
\hline 18 & 0 & 1 & 1 & 1 & 2 & 2 & 2 & 2 & 13 & 3 & 6 & 4 & 4 & 2 & 2 & 2 & 8 & 2 & 2 & 5 \\
\hline 19 & 0 & 0 & 0 & 0 & 0 & 0 & 0 & 0 & 0 & 0 & 0 & 2 & 0 & 0 & 0 & 1 & 0 & 0 & 0 & 0 \\
\hline 20 & 5 & 8 & 7 & 6 & 6 & 14 & 12 & 12 & 7 & 7 & 10 & 7 & 4 & 5 & 5 & 4 & 6 & 6 & 6 & 8 \\
\hline 21 & 5 & 6 & 6 & 5 & 1 & 2 & 2 & 2 & 4 & 5 & 5 & 3 & 3 & 3 & 2 & 2 & 3 & 4 & 3 & 6 \\
\hline 22 & 4 & 4 & 4 & 4 & 3 & 7 & 5 & 4 & 19 & 17 & 13 & 43 & 7 & 5 & 4 & 13 & 8 & 4 & 5 & 2 \\
\hline
\end{tabular}

\section{Região Norte}

No ano de 1985, aproximadamente $60 \%$ das demandas finais das outras regiões induziram os setores Agropecuária (1) e Mineração (2) da região Norte. Merece destaque a região Sul que acionou em maior grau a produção do setor Agropecuária (1) nortista, $56 \%$ de sua demanda final (tabela 11). Em terceiro plano está o setor Material Elétrico (6), no qual estão incluídos os eletrônicos, com participação de $12 \%$ da demanda final da região Sudeste. Os setores Comércio (20) e Transportes 
(21) são acionados de maneira semelhante entre as regiões, ou seja, em torno de $6 \%$ de suas demandas finais. A região Nordeste é a que mais induziu o setor Mecânica (5), enquanto o setor Material de Transporte (7) é induzido mais intensamente pela Sudeste (tabela 11).

Tabela 12

Produção setorial regional induzida pela demanda final de outras regiões, grandes regiões, Brasil, 1995 (em \%)

\begin{tabular}{|c|c|c|c|c|c|c|c|c|c|c|c|c|c|c|c|c|c|c|c|c|}
\hline \multirow[t]{2}{*}{ Setores } & \multicolumn{4}{|c|}{ Norte } & \multicolumn{4}{|c|}{ Nordeste } & \multicolumn{4}{|c|}{ Centro-Oeste } & \multicolumn{4}{|c|}{ Sudeste } & \multicolumn{4}{|c|}{ Sul } \\
\hline & $\mathrm{NE}$ & $\mathrm{CO}$ & $\mathrm{SE}$ & $\mathrm{S}$ & $\mathrm{N}$ & $\mathrm{CO}$ & $\mathrm{SE}$ & $\mathrm{S}$ & $\mathrm{N}$ & $\mathrm{NE}$ & $\mathrm{SE}$ & $\mathrm{S}$ & $\mathrm{N}$ & $\mathrm{NE}$ & $\mathrm{CO}$ & $\mathrm{S}$ & $\mathrm{N}$ & $\mathrm{NE}$ & $\mathrm{CO}$ & $\mathrm{SE}$ \\
\hline 1 & 25 & 25 & 23 & 35 & 3 & 8 & 8 & 11 & 14 & 36 & 63 & 10 & 2 & 6 & 4 & 4 & 8 & 25 & 20 & 43 \\
\hline 2 & 20 & 19 & 19 & 16 & 5 & 7 & 7 & 6 & 8 & 4 & 2 & 7 & 2 & 2 & 3 & 2 & 1 & 1 & 1 & 0 \\
\hline 3 & 1 & 1 & 1 & 1 & 3 & 0 & 0 & 0 & 8 & 3 & 0 & 2 & 18 & 9 & 1 & 4 & 13 & $\mathbf{5}$ & 1 & 0 \\
\hline 4 & 1 & 1 & 1 & 1 & 16 & 4 & $\mathbf{5}$ & 4 & 1 & 0 & 0 & 2 & 15 & 12 & 21 & 23 & 4 & 2 & 8 & 1 \\
\hline 5 & 6 & 1 & 1 & 1 & 4 & 1 & 1 & 1 & 0 & 0 & 0 & 0 & 3 & 3 & 4 & 3 & 4 & 3 & 7 & 1 \\
\hline 6 & 8 & 11 & 14 & 10 & 10 & 1 & 1 & 1 & 1 & 0 & 0 & 0 & 9 & 2 & 5 & 3 & 6 & 1 & 3 & 0 \\
\hline 7 & 2 & 2 & $\mathbf{5}$ & 2 & 3 & 0 & 1 & 0 & 0 & 0 & 0 & 0 & 3 & 4 & 4 & 2 & 1 & 1 & 1 & 0 \\
\hline 8 & 1 & 7 & 3 & 4 & 2 & 0 & 0 & 0 & 1 & 0 & 0 & 0 & 1 & 0 & 2 & 0 & 3 & 1 & 7 & 4 \\
\hline 9 & 3 & 2 & 2 & 2 & 2 & 0 & 0 & 0 & 1 & 1 & 0 & 1 & 3 & 3 & 6 & 3 & 3 & 3 & 7 & 1 \\
\hline 10 & 8 & 3 & 4 & 3 & 1 & 0 & 0 & 0 & 0 & 0 & 0 & 0 & 1 & 3 & 2 & 3 & 0 & 1 & 1 & 0 \\
\hline 11 & 3 & 3 & 3 & 3 & 26 & 35 & 38 & 34 & 13 & 17 & 4 & 9 & 15 & 25 & 23 & 17 & 9 & 11 & 11 & 4 \\
\hline 12 & 0 & 0 & 0 & 0 & 1 & 0 & 0 & 0 & 0 & 0 & 0 & 0 & 1 & 1 & 1 & 1 & 0 & 0 & 0 & 0 \\
\hline 13 & 0 & 0 & 0 & 0 & 2 & 1 & 0 & 1 & 0 & 0 & 0 & 0 & 3 & 3 & 4 & 2 & 2 & 2 & 3 & 0 \\
\hline 14 & 1 & 0 & 0 & 1 & 2 & 4 & 5 & 7 & 1 & 2 & 0 & 2 & 1 & 5 & 3 & 2 & 2 & 6 & 3 & 1 \\
\hline 15 & 0 & 0 & 0 & 0 & 0 & 0 & 0 & 0 & 0 & 0 & 0 & 0 & 0 & 0 & 0 & 0 & 0 & 1 & 1 & 1 \\
\hline 16 & 4 & 3 & 3 & 3 & 3 & 3 & 3 & 5 & 5 & 10 & 6 & 2 & 2 & 5 & 3 & 3 & 9 & 20 & 8 & 24 \\
\hline 17 & 4 & 3 & 2 & 2 & 0 & 0 & 0 & 0 & 0 & 0 & 0 & 0 & 1 & 1 & 2 & 1 & 0 & 1 & 1 & 0 \\
\hline 18 & 2 & 2 & 2 & 2 & 4 & 3 & 4 & 3 & 12 & 2 & 3 & 2 & 7 & 2 & 2 & 2 & 16 & 3 & 4 & 7 \\
\hline 19 & 0 & 0 & 0 & 0 & 0 & 0 & 0 & 0 & 1 & 0 & 0 & 4 & 0 & 0 & 0 & 1 & 0 & 0 & 0 & 0 \\
\hline 20 & 5 & 11 & 9 & 9 & 8 & 22 & 17 & 18 & 4 & 3 & 4 & 3 & 3 & 3 & 3 & 3 & 5 & 5 & 5 & 6 \\
\hline 21 & 2 & 3 & 3 & 2 & 1 & 2 & 2 & 2 & 2 & 3 & 2 & 2 & 3 & 4 & 3 & 2 & 3 & 4 & 3 & 5 \\
\hline 22 & 2 & 4 & 4 & 4 & 4 & 7 & 7 & 6 & 28 & 18 & 13 & 54 & 9 & 6 & 5 & 18 & 10 & 5 & 5 & 2 \\
\hline
\end{tabular}

O ano de 1995 mostra que a participação das demandas finais das outras regiões sobre os setores Agropecuária (1) e Mineração (2) da região Norte reduziu para $45 \%$. Isto se deu em função da queda da demanda final das regiões relativamente ao setor Agropecuária (1), já que para o setor Mineração (2) foi constatado um acréscimo. As demandas finais das outras regiões sobre a região Norte elevam suas participações para os setores Material Elétrico (6) e Comércio (20) em 1995. Novamente, cabe destacar a região Nordeste como a que mais induziu os setores Mecânica (5) e Indústria da Borracha (10), a região Sudeste o setor Material de Transporte (7) e a região Centro-Oeste o setor Madeira e Mobiliário (8) (tabela $12)$.

A conclusão que se chega para a região Norte é que maior número de setores foram mais intensamente acionados pelas demandas finais das outras regiões em 1995. Também, a participação da demanda final das outras regiões nos setores nortistas foi mantida ou se elevou para a maioria dos setores comuns entre 1985/95, 
o que permite afirmar que a interação entre o Norte e as demais regiões brasileiras foi levemente incrementada entre estes anos. Por fim, deve-se notar o crescimento da importância do Nordeste enquanto demandante de setores da região Norte.

\section{Região Nordeste}

A estrutura econômica do Nordeste mostrou-se diversificada, incorporando setores importantes como Metalurgia (4) e Química (11). No primeiro caso, cabe destacar a participação da região Norte, com 21\% de sua demanda final em 1985 e $16 \%$ em 1995 e, no segundo, a região Sudeste com $32 \%$ e $38 \%$, respectivamente (tabelas 11 e 12).

Os setores Mineração (2) e Química (11), juntos, responderam, em média, por $43 \%$ das demandas finais da outras regiões para com a produção do Nordeste em 1985. Esta participação caiu, em média, para 39\% em 1995, como conseqüência exclusiva da redução, pela metade, da participação da Mineração (2), uma vez que as regiões elevam suas demandas finais para com o setor Química (11). Outro setor que se relaciona com as quatro regiões é o Comércio (20), no qual se sobressai a região Centro-Oeste com 14\% de sua demanda final em 1985 e 22\% em 1995 .

A região Norte foi a única que se apresentou como grande demandante do setor Material Elétrico (6) da região Nordeste nos dois anos em análise. Considerando a posição do Nordeste, salientada na análise do Norte, constatou-se o crescimento do intercâmbio entre essas duas regiões de 1985 para 1995. O período 1985/95 revelou para a região Nordeste a permanência dos setores demandados pela outras regiões, embora a participação das demandas finais destas regiões tenha se mantido ou reduzido para a maioria dos setores.

\section{Região Centro-Oeste}

A região Centro-Oeste apresentou, em 1985, 6 e, em 1995, 4 setores mais acionados pelas demandas de outras regiões, sendo que apenas 2 foram demandados por todas as regiões (tabelas 11 e 12). O destaque é o setor Agropecuária (1), importante na composição da demanda final da região Sudeste, com 53\% e 63\%, e da Nordeste, com 33\% e 36\%, em 1985 e 1995, respectivamente. Na segunda colocação está o setor Serviços (22) para o qual se sobressai a região Sul com $43 \%$ e $54 \%$ de sua demanda final para com o Centro-Oeste em 1985 e 1995, respectivamente (tabelas 11 e 12). É interessante registrar o crescimento da participação, em 1995, dos setores Química (11) e Produtos Alimentares (16) e a redução da participação dos setores Mineração (2), Minerais não Metálicos (3), 
SIUP e Comunicações (18), Comércio (20) e Transportes (21) como demandantes do Centro-Oeste . Em número de setores, as regiões Norte e Nordeste são as mais importantes demandantes do Centro-Oeste, acionando, com mais intensidade, 4 setores em 1985 e em 1995 (tabelas 11 e 12).

\section{Região Sudeste}

A estrutura diversificada da região Sudeste nos anos de 1985 e 1995 pode ser visualizada nas tabelas 11 e 12. Em 1985, 7 setores foram acionados mais fortemente pelas demandas finais da outras regiões, dos quais 2 foram demandados por todas elas, Metalurgia (4) e Química (11). O setor Metalurgia (4) foi mais demandado pela região Sul, $22 \%$ de sua demanda final, enquanto o setor Química (11) recebeu maior impacto da demanda final da região Centro-Oeste, $26 \%$ (tabela 11).

Em 1995, 5 setores foram mais demandados por outras regiões, com destaque para Metalurgia (4), Química (11) e Serviços (22). Novamente, o setor Metalurgia (4) foi mais demandado pela região Sul, 23\%, seguido pelo setor Serviços (22), $18 \%$. O setor Química (11) foi acionado de forma mais significativa pela região Nordeste, $25 \%$ de sua demanda final (tabela 12).

Duas constatações importantes que diferenciaram o comportamento da economia da região Sudeste das demais foram: a) a grande maioria dos seus setores foi acionada pela demanda final das outras regiões e b) a participação das demandas finais das demais regiões no Sudeste se elevou para a maioria dos setores comuns aos anos estudados.

\section{Região Sul}

A região Sul apresentou a estrutura produtiva bastante integrada entre 1985/95, com grande parte dos setores sendo demandados pelas outras regiões (tabelas 11 e 12).

Os setores Agropecuária (1) e Produtos Alimentares (16), juntos, foram responsáveis, em média, por $33 \%$ das demandas finais de outras regiões sobre a produção da região Sul em 1985 e 39\% em 1995. Os destaques desta indução ficam com as regiões Sudeste e Nordeste. Para a Agropecuária (1) as participações foram de $33 \%$ para o Sudeste e $19 \%$ para o Nordeste em 1985 e $43 \%$ e $25 \%$ em 1995, respectivamente. Para o setor Produtos Alimentares (16) as proporções atingiram $24 \%$ para o Sudeste e $19 \%$ para o Nordeste em 1985 e $24 \%$ e $20 \%$ em 1995, respectivamente. Cabe salientar, ainda, os setores Química (11) e Comércio 
(20) como secundariamente acionados pelas demandas finais das outras regiões, embora, em ambos os casos, note-se uma redução na magnitude das demandas regionais nos anos estudados.

A análise desenvolvida permitiu constatar algumas tendências importantes entre 1985 e 1995 para as regiões brasileiras no que se refere à demanda final de outras regiões: a) as regiões Sudeste e Sul apresentam estruturas produtivas mais integradas, com maior número de setores-chave para a dinâmica da economia nacional, confirmando as constatações feitas pelos índices de ligações; b) a participação das demandas finais das outras regiões se manteve constante ou reduziu para a maioria dos setores comuns aos anos analisados nas regiões, exceção feita para as regiões Sudeste e, em menor grau, Norte; c) a participação das demandas finais das outras regiões se elevou para o setor Serviços (22) em todas as regiões e d) houve uma redução da interação entre regiões, revelada pelo menor número de regiões participando com suas demandas finais nos setores de outras regiões.

\section{Considerações Finais}

A contribuição principal desta pesquisa refere-se às inferências sobre as relações setoriais e inter-regionais considerando as 5 grandes regiões brasileiras para os anos de 1985 e 1995.

A análise dos índices de ligações de Rasmussen/Hirschman, considerando o critério restrito, apontou o setor Têxtil (14) como chave para todas as regiões brasileiras além de uma redução no número de setores-chave entre 1985 e 1995 . O método GHS amplia o leque se setores dinâmicos, apresentando Agropecuária (1), Produtos Alimentares (16), Comércio (20) e Serviços (22) como chave para todas as regiões.

Para o sistema inter-regional, a região Sudeste se manteve como pólo dinâmico na economia brasileira.

A pesquisa detectou certa dinâmica na estrutura produtiva da região Nordeste, além do crescimento do intercâmbio entre esta região e a Norte, o que pode estar indicando a existência de certo pólo de desenvolvimento entre essas regiões. Por fim, constatou-se maior independência entre as regiões brasileiras, provavelmente, fruto do crescimento da integração da estrutura produtiva nacional com o exterior entre 1985 e 1995.

Como sugestão para futuros trabalhos, propõe-se a interação do sistema interregional da presente análise com o Mercosul, União Européia e outros blocos econômicos, para que as relações econômicas das regiões brasileiras no contexto internacional possam ser estabelecidas de forma explícita. 


\section{Referências}

Baer, W. (1996). A Economia Brasileira. Forense Universitária, São Paulo.

Bonelli, R. \& Gonçalves, R. R. (1998). Para onde vai a estrutura industrial brasileira? In A Economia Brasileira Em Perspectiva, pages 617-664. IPEA, Rio de Janeiro. Volume 2, capítulo 16.

Cella, C. (1984). The input-output measurement of interindustry linkages. Oxford Bulletin of Economics and Statistics, 46:73-84.

Clements, B. (1990). On the decomposition and normalization of interindustry linkages. Economics Letters, 33:337-340.

Conjuntura Econômica (1997). Indicadores econômicos. Indicadores Econômicos, $51(8)$.

Crocomo, F. C. (1998). Análise das relações inter-regionais e intersetoriais na economia brasileira em 1985: Uma aplicação de insumo-produto. Tese de Doutorado - Escola Superior de Agricultura Luz de Queiroz, Universidade de São Paulo.

Guilhoto, J. (1999). Matriz de insumo-produto inter-regional do Brasil para 1995. Escola Superior de Agricultura Luiz de Queiroz, Universidade de São Paulo (documento de circulação interna).

Guilhoto, J. J. M., Sonis, M., \& Hewings, G. J. D. (1996). Linkages and multipliers in a multiregional framework: Integracions of alternative approaches. Urbana: University of Illinois, Regional Economics Applications Laboratory. Discussion Paper, 96-T-8.

Guilhoto, J. J. M., Sonis, M., Hewings, G. J. D., \& Martins, E. B. (1994). índices de ligações e setores-chave na economia brasileira: 1959/80. Pesquisa e Planejamento Econômico, 24(2):287-314.

Hewings, G. J. D. (1982). The empirical identification of key sectors in an economy: A regional perspective. The Developing Economies, 20:173-195.

Hirschman, A. O. (1958). The Strategy of Economic Development. Yale University Press, New Havery.

Instituto Brasileiro de Geografia e Estatística (1995). Matriz de relações intersetoriais Brasil 1985. Rio de Janeiro: IBGE. 
Instituto Brasileiro de Geografia e Estatística (1997a). Anuário estatístico do Brasil 1996. Rio de Janeiro: IBGE.

Instituto Brasileiro de Geografia e Estatística (1997b). Matriz de relações intersetoriais Brasil 1995. Rio de Janeiro: IBGE.

McGilvray, J. (1977). Linkages, key sectors and develolpment strategy. In Leontief, W., editor, Structure, System and Economic Policy, chapter 4, pages 49-56. Cambridge University Press, Cambridge.

Melo, H. P., Rocha, F., Ferraz, G., Sabbato, G., \& Dweck, R. (1998). O setor serviços no Brasil: Uma visão global - 1985/95. In A Economia Brasileira Em Perspectiva - 1998, chapter 17, pages 665-712. IPEA, Rio de Janeiro.

Rasmussen, P. (1956). Studies in Intersectoral Relations. North Holland, Amsterdan. 